\title{
Cyclic anhydrides as powerful tools for bioconjugation and smart delivery
}

Maria Vittoria Spanedda* and Line Bourel-Bonnet

Laboratoire de Conception et Application de Molécules Bioactives, 3Bio team, ITI InnoVec, UMR 7199 - CNRS / Université de Strasbourg, Faculté de Pharmacie, 74 route du Rhin, BP 60024, 67401 Illkirch Cedex, France.

* Corresponding author, to whom correspondence should be addressed: spanedda@unistra.fr, Phone: +33 368854 120; Fax: +33 368854306.

\begin{abstract}
Cyclic anhydrides are potent tools for bioconjugation, therefore they are broadly used in the functionalization of biomolecules and carriers. The pH-dependent stability and reactivity, as well as the physical properties, can be tuned by the structure of the cyclic anhydride used, thus their application in smart delivery systems has become very important. This review intends to cover the last updates in the use of cyclic anhydrides as pH-sensitive linkers, their differences in reactivity and the latest applications found in bioconjugation chemistry, or chemical biology and when possible, in drug delivery.
\end{abstract}

\section{Key-words}

Cyclic anhydride, linker, pH-sensitive, charge reversal, smart delivery 


\section{Introduction}

By definition, and etymologically speaking an anhydride function is obtained by dehydration of two acids. In other words, an anhydride function can be seen as the concomitant protection of a first acid and the activation of a second one. Cyclic anhydrides are no-end ring molecules and the majority are those derived from carboxylic diacids. Other acids can be involved but are not considered in this review as the point of the present review is to focus on cyclic carboxylic anhydrides. Due to energetic and stability reasons, commercially available cyclic anhydrides are usually 5- to 6-member dehydrated rings (Figure 1), yet some of them can be slightly contaminated by the corresponding hydrated diacid. 


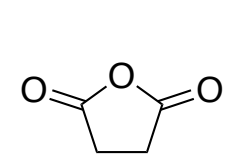

succinic anhydride<smiles>CCCCCC/C=C/C1CC(=O)OC1=O</smiles>

octenylsuccinic anhydride<smiles>CC(=O)SC1CC(=O)OC1=O</smiles>

S-acetylmercaptosuccinic anhydride<smiles>O=C1CCCC(=O)O1</smiles>

glutaric anhydride<smiles>O=C1CCCCC(=O)O1</smiles>

adipic anhydride<smiles>O=C1COCC(=O)O1</smiles>

glycolic anhydride<smiles>C=C1CC(=O)OC1=O</smiles>

itaconic anhydride<smiles>O=C1C=CC(=O)O1</smiles>

$$
\text { maleic }
$$
anhydride<smiles>CC1=CC(=O)OC1=O</smiles>

citraconic anhydride<smiles>CC1=C(C)C(=O)OC1=O</smiles>

dimethylmaleic anhydride<smiles>O=C(O)CC1=CC(=O)OC1=O</smiles>

cis-aconitic anhydride<smiles>O=C(O)CCC1=CC(=O)OC1=O</smiles>

2-(2'-carboxyethyl) maleic anhydride<smiles>CC1=C(CCC(=O)O)C(=O)OC1=O</smiles>

1-methyl-2-(2'-carboxyethyl) maleic anhydride

Figure 1: cyclic anhydrides predominantly used in bioconjugation, on which the present review focuses.

Cyclic anhydrides are crucial molecular tools in bioconjugate chemistry. ${ }^{1}$ Above all, they are one of the most obvious homobifunctional reagents, due to their intrinsic reactivity in mild conditions as electrophilic acid derivatives towards nucleophiles, especially amines and alcohols, which are the most common functional groups in biomolecules (Scheme 1). As one carboxylic group is easily 
activated in the anhydride bond, the reaction does not need any coupling agent such as deleterious carbodiimides, thus and advantageously, no secondary products are obtained after conjugation. All those properties made cyclic anhydrides partners of choice in what can be defined as click reactions, although an excess of anhydride is usually needed to minimize hydrolysis of the latter. In the particular case of amino acids, recently, imide formation between anhydrides and guanidine was reported as an efficient tool for bioconjugation on arginine, ${ }^{2}$ otherwise cysteine sulfhydryl groups, tyrosine phenolate ions, and the imidazolyl ring of histidine are also able to react with anhydrides as nucleophiles, but their acylation is reversible and consequently, it is not used in bioconjugation due to this lability. Reactions with alcohol functions to result in esters (for instance in carbohydrates) are easily performed in organic media with little amounts of water, but in aqueous media they are truly inhibited by competition with hydrolysis. For this reason, bioconjugation techniques involving cyclic anhydrides essentially focus on reactions with amines.

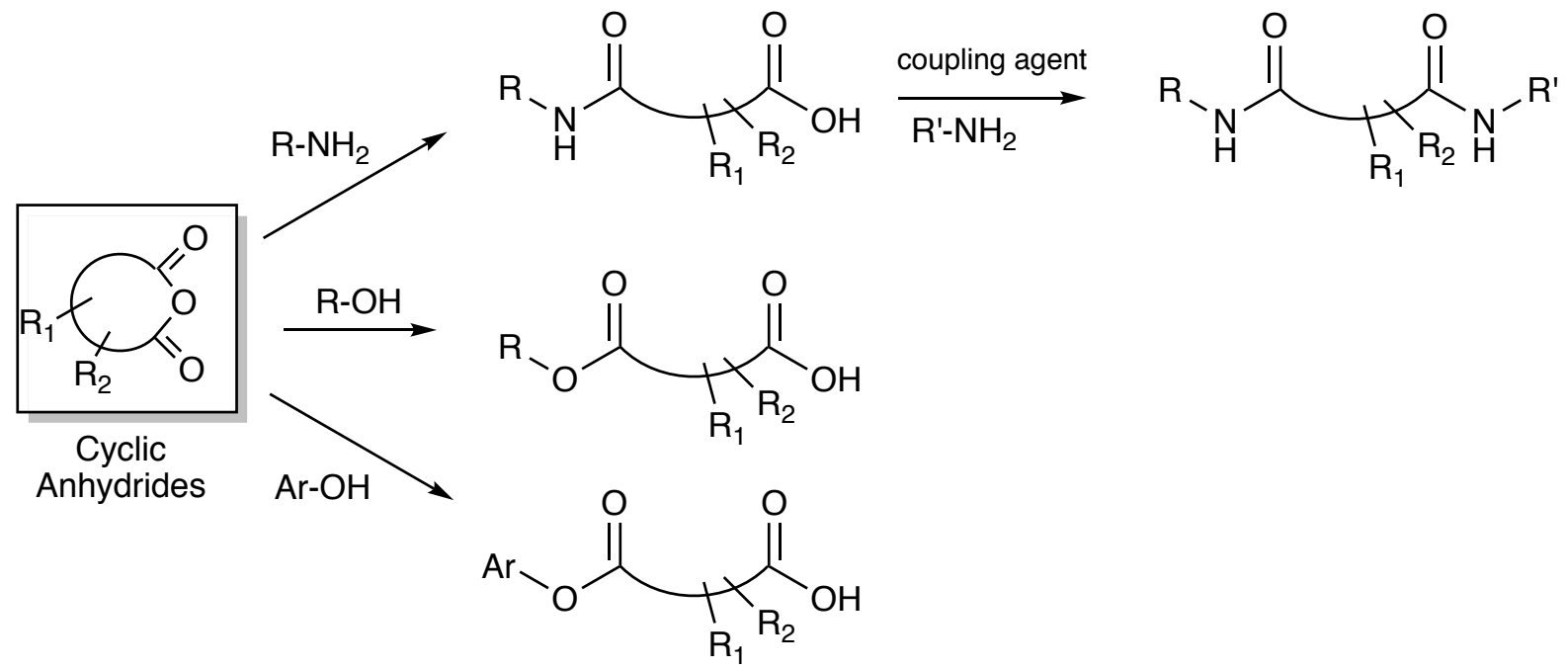

Scheme 1: general reactivity of cyclic anhydrides with amines, alcohols and phenols. 
Modification of biomolecules by anhydrides, though, does not only provide direct covalent binding to another molecular entity. It is also a very efficient manner to modify the total charge of the corresponding biomolecule, by eliminating a positive charge contribution and, at the same time, adding the negative charge of the free carboxylate generated by the opening of the cycle. While this phenomenon must be carefully controlled to avoid denaturation or loss of biological properties, it can also represent an advantage: this concept of "charge reversal" (Scheme 2) can be exploited whenever a dramatic variation of the global charge of any biomolecule can trigger a specific biological phenomenon ${ }^{3}-$ for example, it can lead to an increase of internalization by specific cell compartments or tissues, as we will see later.
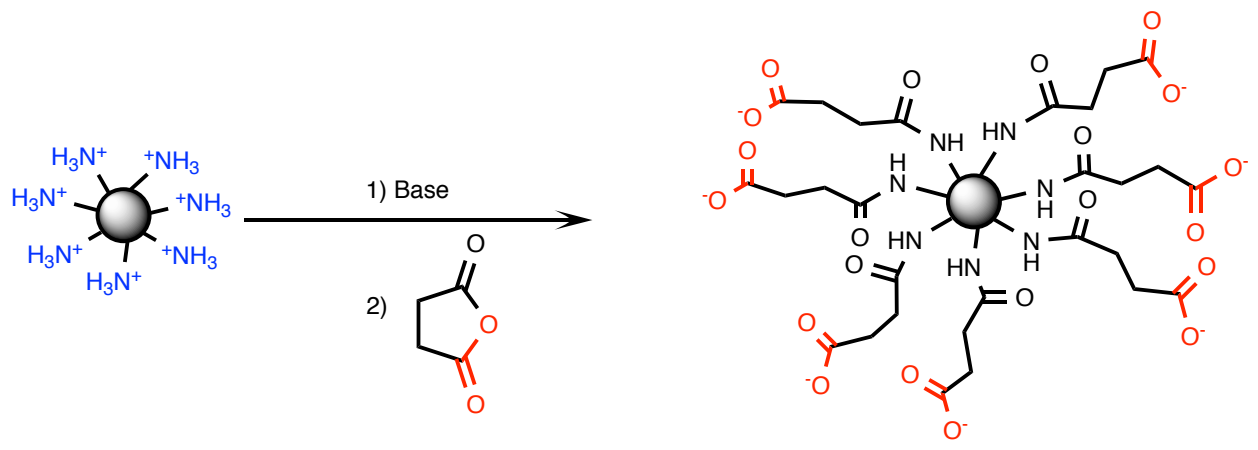

Scheme 2: charge reversal principle.

Moreover and in recent studies, especially maleic anhydride derivatives have been revealed to have the ability to form amides that can be easily hydrolyzed at mild acidic $\mathrm{pH}$ values. This characteristic makes them precious tools to produce $\mathrm{pH}$-sensitive linkers, for example to target compartments where the $\mathrm{pH}$ is slightly altered in the human body. For instance, it is well known that inflammatory and cancer tissues have weaker $\mathrm{pH}$ values (5-6) than other compartments (7.4), so 
delivering at a slightly lower $\mathrm{pH}$ could afford a valuable selectivity for the abovementioned tissues. Intracellular organelles so-called lysosomes also show an acidic $\mathrm{pH}$ of 4 , thus the conception of $\mathrm{pH}$-sensitive systems can improve the selectivity of the delivery in that cell compartment.

As we stated above, the principal side-reaction of anhydrides is their hydrolysis into the formation of the corresponding, less or even unreactive dicarboxylic compound. This side reaction can be avoided using an excess of anhydride, acting also as a dehydrating agent, in the medium. As at least one carboxylic acid will be released during the conjugation or the hydrolysis, a decrease in $\mathrm{pH}$ will be expected, which may lead to amine protonation and subsequent loss of reactivity. For this reason, the use of a buffered medium or the addition of a base to restore the desired $\mathrm{pH}$ is recommended.

In the following, the first part is dedicated to the common chemical routes to get cyclic carboxylic anhydrides, with some emphasis on the synthesis of maleic anhydride and derivatives thereof. A second part describes the most popular cyclic anhydrides and for each one, some examples of their use in bioconjugation chemistry - and when available, in drug delivery - will be given. The paragraphs dedicated to maleic anhydride itself and its derivatives are deliberately detailed, given the importance of such compounds in bioconjugate chemistry. The difference in reactivity, the input and the value of each anhydride are discussed.

\section{Part 1 - Synthesis}

General synthesis of cyclic carboxylic anhydrides 
Conventionally, cyclic anhydrides are obtained from the corresponding dicarboxylic acid. Few strategies of synthesis are currently available for these products, and they often make use of toxic reagents or harsh conditions. One popular strategy is the dehydration of dicarboxylic acids with acylating or dehydrating compounds (acid chlorides, phosgene, thionyl chloride, benzenesulfonyl chloride, ketene, phosphorus pentoxide or acetic anhydride), but yields tend to be low when the substrate is acid sensitive. ${ }^{4}$ More recently, the use of Lewis acids to catalyze that dehydration has proved to produce anhydrides in quantitative yields in short times and milder conditions, namely with either metal-salen complexes ${ }^{5}$ or with $\mathrm{MgCl}_{2}$ and $\mathrm{Boc}_{2} \mathrm{O} .{ }^{4}$ The synthesis has been described as effective for the preparation of succinic, glutaric, adipic, pimelic, methylsuccinic, itaconic, diphenic, camphoric, phenylsuccinic, maleic and phthalic anhydrides. ${ }^{4}$

\section{Synthesis of maleic anhydride and derivatives thereof}

The first straightforward synthesis of maleic anhydride has been reported in 1930 and was performed by azeotropic distillation of maleic acid with xylene or tetrachloroethane, ${ }^{6}$ leading to the desired anhydride in excellent yields (89\%). That was an impressive result considering that previously known syntheses by dehydration of the same diacid led mostly to isomerization to fumaric acid. Alternatively, oxidation of $\mathrm{C}_{4}$ hydrocarbons as 1,3-butandiene or furan using vanadium and molybdenum oxides was reported with moderate yields (around 50\%). ${ }^{7}$ More recently, an environmentally friendly synthesis starting from biomass-derived levulinic acid, also with vanadium oxide catalysis, was described to give maleic anhydride in $71 \%$ yield (Scheme 3 ). ${ }^{8}$ 


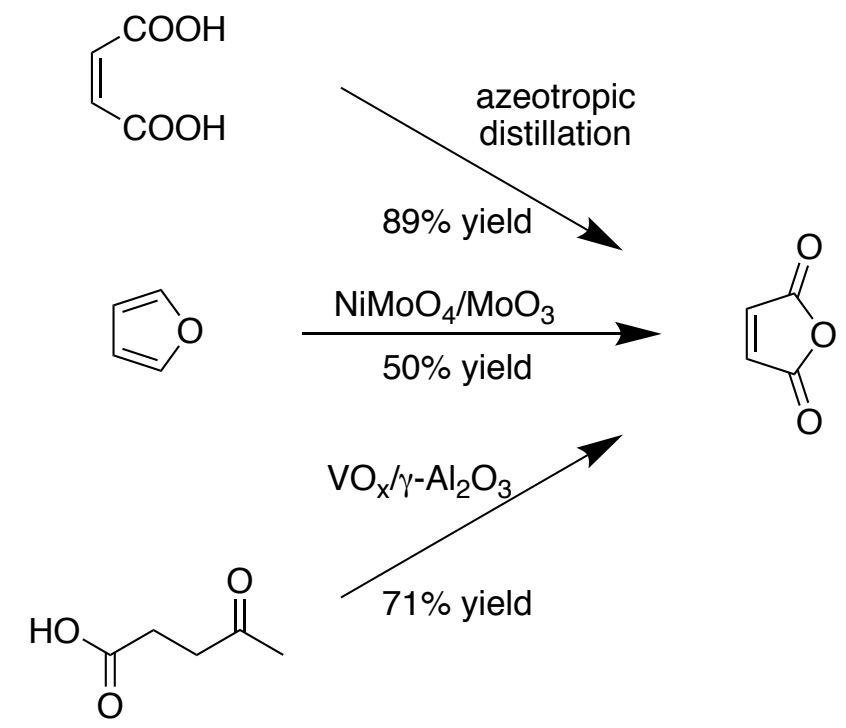

Scheme 3: three popular routes toward maleic anhydride. ${ }^{5,6,7}$

For substituted maleic anhydrides, other strategies are available. For 2-(2'carboxyethyl) maleic anhydride and 1-methyl-2-(2'-carboxyethyl) maleic anhydride, a Horner-Wadsworth-Emmons reaction between dimethyl-2oxoglutarate and either triethylphosphonoacetate or triethylphosphonopropionate, followed by the saponification of the esters by a strong base and the subsequent cyclisation in acidic conditions, is a very efficient strategy (Scheme 4). ${ }^{9}$ An alternative can be the addition of organocopper reagents to acetylenic esters, followed by the reaction with an appropriate electrophile, deprotection and dehydration. ${ }^{10}$

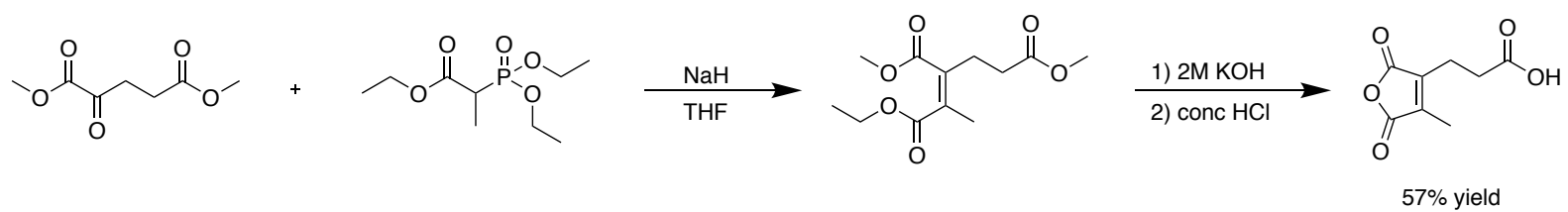

Scheme 4: Wadsworth-Emmons reaction to get 2-(2'-carboxyethyl) substituted maleic anhydrides. ${ }^{9}$ 
Disubstituted aromatic maleic anhydrides could also be prepared from $\alpha$ halogenohydrazide ${ }^{11}$ in $55-85 \%$ yield (Scheme 5) to afford symmetrically or asymmetrically substituted molecules after hydrolysis of the corresponding $\mathrm{N}$ aminomaleimides.<smiles>[R]C(=O)NNC(=O)C(Br)Br</smiles>

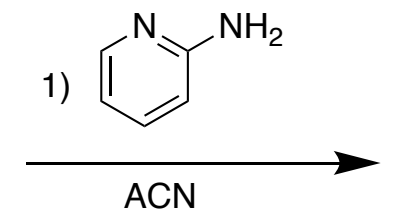

2) $\mathrm{NaOH}, \mathrm{EtOH}$

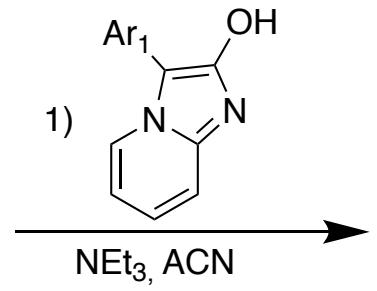

2) $\mathrm{NaOH}, \mathrm{EtOH}$<smiles>O=C1OC(=O)C(Br)=C1Br</smiles>

symmetric anhydrides

$55-85 \%$ yield<smiles>O=C1OC(=O)C(Br)=C1Br</smiles>

asymmetric anhydrides

Scheme 5: Routes to symmetric and asymmetric arylated maleic anhydrides. ${ }^{\mathbf{1 1}}$

In situ anhydride synthesis

Strategies to form anhydrides directly on nanoparticles are available. Thereby, carbon dots obtained by thermal decomposition of citric acid may form valuable anhydride functions at their surface during the heating process (Scheme 6). ${ }^{12}$<smiles>O=C(O)CC(O)(CC(=O)O)C(=O)O</smiles>

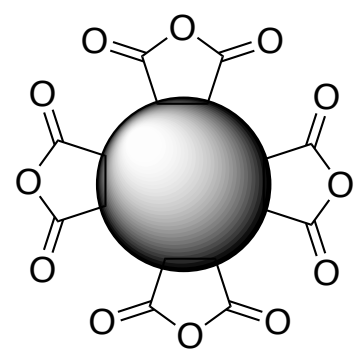

Scheme 6: Formation of anhydrides on carbon dots. ${ }^{\mathbf{1 2}}$ 
To be more precise, single-ring anhydrides are the first to be dealt with (Sections 1-12), then the double-ring ones (Section 13). Within the single-ring anhydrides, the most common 5- and 6-membered ones are first presented, then the rigid and unsaturated ones.

\section{1- Succinic anhydride}

The simplest saturated cyclic anhydride, succinic anhydride is one of the most popular homobifunctional reagents in bioconjugation. Consequently, countless examples can be found in literature of its use as a linker for polymer functionalization or, more generally, in organic synthesis. In the field of bioconjugation, its use for protein modifications generally increases the apparent protein solubility, for example, that of wheat gluten at $\mathrm{pH} 5$, by promoting disaggregation to smaller molecular weight fractions, or that of casein by shifting the isoelectric point to lower $\mathrm{pH} .{ }^{13}$ Modification of human serum albumin (HSA) with succinic anhydride on the lysine residues involves a modification of the charge from +1 to -1 per residue (Scheme 2), and this inhibits HSA cell binding and fusion of the HIV-1 virus. ${ }^{14,15}$ Inhibition of the influenza virus fusion by the same modified HSA and $\beta$-lactoglobulin A was also observed. ${ }^{16}$

In the above-mentioned examples, the function that reacts principally is the $\varepsilon$ amine of the lysine. Succinic anhydride was also reported to react with hydroxyl groups of tyrosine, serine and threonine in proteins. While phenolate ester derivatives with tyrosine are unstable at $\mathrm{pH}>5.0$, aliphatic hydroxylic derivatives are relatively stable until cleavage by hydroxylamine under basic conditions. ${ }^{17}$ Interestingly, succinic anhydride can easily react with hydroxyl groups encountered in nucleic acids, which can represent an advantage in their synthesis ${ }^{18}$ and in the modification of their analogs. ${ }^{19}$ 
In supramolecular systems, succinic anhydride has been used to link doxorubicin to polyethylene imine (PEI) with robust amide bonds ${ }^{20}$ and also indomethacin to a $\mathrm{pH}$ and temperature-sensitive poly(3-ethyl-3-(hydroxymethyl)oxetane-starpoly(2-(dimethylamino) ethyl methacrylate copolymer. ${ }^{21}$ Recombinant streptavidin conjugates were functionalized with succinic anhydride or 1,2cyclohexanedione, with a better biotin affinity for the former. ${ }^{22}$ In addition, zwitterionic chitosan modified with succinic anhydride for stealth coating was reported, ${ }^{23}$ for which the isoelectric point could be tuned from $\mathrm{pH} 4.9$ to 7.1 and could avoid deleterious protein absorption at physiological $\mathrm{pH}$.

It is worth to highlight that such modifications do not need any activating or leaving group, which is instead generally needed when crosslinking between two molecules. In this case, the use of classical coupling reagents, such as the couple 1-ethyl-3-(3-dimethylaminopropyl)carbodiimide/N-hydroxysuccinimide (EDCI/NHS), or the presence of a suitable leaving group is needed to activate the free carboxylic acid.

Polyamidoamine (PMAM) dendrimers have been modified with succinic, cyclohexanedicarboxylic and phthalic anhydrides prior to conjugation to phenylalanine. In this case, the carboxyl-terminal dendrimer obtained via crosslinking of phenylalanine with anhydrides showed upper critical solution temperature-type sensitivity in acidic solutions, while amino-terminal dendrimers, modified directly with phenylalanine without use of a crosslinker, showed lower critical solution temperature-type sensitivity at neutral $\mathrm{pH} .{ }^{24}$ Hydrogel composed of dextran methacrylate modified with, not only succinic, but also glutaric and phthalic anhydrides were reported ${ }^{25}$ for the delivery of 
ibuprofen. The anhydride linker has an influence on the hydrogel swelling at different $\mathrm{pH}$, being greater for succinic and smaller for phthalic anhydride, probably related to the chain hydrophilicity. Swelling was also greater at $\mathrm{pH} 7.4$ than in double-distilled water, due to the more complete ionization of the carboxylic groups, while it is reduced when the ionic strength of the medium is increased 26 .

\section{2- Octenylsuccinic anhydride}

The amphiphilic structure of octenylsuccinic anhydride, containing a pH-sensitive hydrophilic anhydride group and a lipophilic chain, has been used to improve the properties of several polymers, such as starch, konjac glucomannan, Arabic gum, agarose and chitosan to obtain food additives. The benefits given by addition of this compound are various: 1) reactivity with amines and alcohols is higher than with other crosslinkers, without use of toxic coupling agents; 2) pH-sensitivity can be exploited; 3) the octenyl chain allows the formation of micelles that can trap hydrophobic compounds, thus increasing loading capacity of hydrophobic drugs. Studies on loading of curcumin and quercetin in chitosan-modified nanoparticles have showed a very good biocompatibility and a high release profile. ${ }^{27}$

\section{3- S-acetyl mercaptosuccinic anhydride (SAMSA)}

Thanks to its thiolated group, S-acetyl mercaptosuccinic anhydride can be used to introduce a thiol on a molecule with free amino groups ${ }^{28}$ at room temperature or lower and in physiological conditions (scheme 7). The S-acetyl group can be 
easily deacetylated by a nucleophilic reagent, like imidazole or hydroxylamine, but is otherwise stable for days at $\mathrm{pH} 9.5$ or lower. ${ }^{29}$

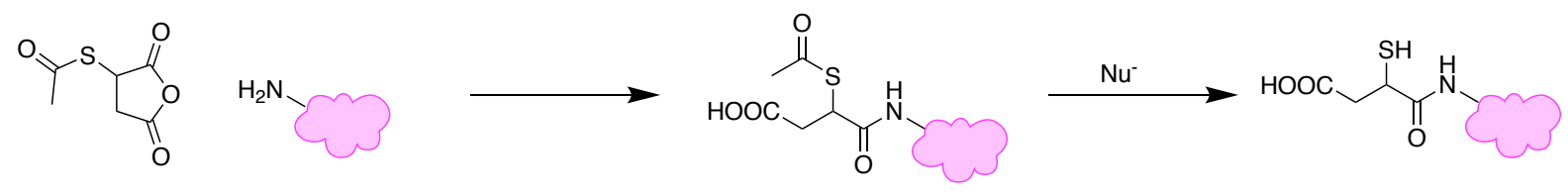

Scheme 7: S-acetyl mercaptosuccinic acid reactivity ${ }^{29}$

4- Glutaric anhydride and analogs (3-methylglutaric and 3,3-dimethylglutaric anhydride)

Glutaric anhydride has one more methylene link than succinic anhydride, and shows the same overall reactivity. The slight difference between the two resides in the length of the linker obtained after opening and in the ring tension, which is higher for the 6-membered ring. ${ }^{30}$ Nonetheless, non-substituted glutaric anhydride is not commonly used for the modification of proteins, while some examples of modification by its methylated analogs 3-methylglutaric anhydride and 3,3-dimethylglutaric anhydride have been reported in food chemistry especially, on egg white proteins. ${ }^{31}$

Glutaric anhydride has proved to be an efficient linker in mesoporous silica material functionalized with amines and bearing an enzyme, due to the electrostatic attraction between its carboxylate and the lysine amino group of the enzyme..$^{32}$

3-methylglutaric anhydride has been used to functionalize dextran ${ }^{33}$ and the modified carbohydrate polymer was coupled to phospholipids so as to obtain $\mathrm{pH}$ sensitive liposomes. Moreover, to confer $\mathrm{pH}$-sensitivities and fusogenicity to liposomes, interaction of phospholipids with succinylated (Suc) poly(glycidol) 
(PG) was achieved, and the influence of the anhydride linker was studied using glutaric (Glut), 3-methylglutaric (MGlut) and 1,2-cyclohexanedicarboxylic (Chex) anhydrides. ${ }^{34}$ The resulting polymers were soluble at physiological $\mathrm{pH}$ but precipitated at acidic $\mathrm{pH}$ values, with values of $\mathrm{pH}$ of precipitation following the order SucPG $<$ GlutPG $<$ MGlutPG $<$ CHexPG, consistent with the number of carbon atoms in the chain, where SucPG precipitated at $\mathrm{pH} 4.0$ and CHexPG precipitated at 5.4. MGlutPG proved to be the conjugate displaying the best properties in terms of hydrophobicity and pH-sensitivity.

\section{5- Adipic anhydride}

The seven membered cyclic adipic anhydride is prone to polymerize easily into polyadipic acid (PAA), even at $0^{\circ} \mathrm{C}$, but can also be efficiently used as a crosslinker between polymers, like cellulose, ${ }^{35}$ to formulate drugs as amorphous solid dispersions so as to overcome their scarce solubility in water. The advantage of adipic anhydride in this case is its aliphatic chain, long enough to avoid back cyclization to the seven-membered ring, stabilizing greatly the ester group. To avoid homopolymerization side-products, double distillation of the anhydride seems the easiest and most effective strategy to date. ${ }^{35}$ The rate of polymerization can be quantified by ${ }^{1} \mathrm{H}$ NMR: in the polymer $\mathrm{PAA}-\mathrm{CH}_{2} \mathrm{CH}_{2}$ - and $\mathrm{CH}_{2}-\mathrm{CO}-\mathrm{O}-\mathrm{CO}-\mathrm{CH}_{2}$ signals are respectively observed at 1.75 and $2.5 \mathrm{ppm}$, while in the monomer the corresponding signals are found at 2.0 and 2.8 ppm. PAA can effectively be removed from the crude by washing with hot water. ${ }^{35}$ Cellulose derivatives were soluble in a wide range of organic solvents, like acetone, DMSO and THF. 35 


\section{6- Diglycolic anhydride}

In the family of aliphatic cyclic anhydrides, diglycolic anhydride is the most hydrophilic. It can be seen as the 0 -analog of glutaric anhydride. The replacement of the central methylene link - $\mathrm{CH}_{2}$ - by its isostere oxygen -O- introduces a H-bond acceptor site into the spacer, like those conveyed by ethylene glycol moieties. Very recently, this anhydride was used in the one-pot synthesis of a stable linker for an antibody-drug conjugate, ${ }^{36}$ the free carboxylate being able to further react with the lysine of an anti-CD4 antibody. Another application is the preparation of hydrophilic $\mathrm{Fe}_{3} \mathrm{O}_{4}$ nanoparticles to trap glycopeptides in human saliva. ${ }^{37}$ In this case, diglycolic anhydride reacts with 1,3,5-triformylphloroglucinol on one side and amines on the particle surface on the other side, to afford a hydrophilic coating for the nanoparticles.

\section{7- Itaconic anhydride - monomer and corresponding copolymers}

Obtained by pyrolysis of citric acid, itaconic anhydride has an extra-cycle double bond that allows polymerization, but also reacts as a dienophile in Diels-Aldertype reactions. In basic conditions, or at high temperatures, it can isomerize to citraconic anhydride, thus contamination with the latter cannot be avoided. ${ }^{38}$ Itaconic anhydride has been used to get a linker in conjugation of poly- $N$ isopropylacrylamide with $\beta$-galactosidase. ${ }^{39}$ The bioconjugate shows better thermal and storage stabilities than the native enzyme, as well as a lower Michaelis-Menten constant, and was successfully used for the synthesis of galacto-oligosaccharides from lactose.

As previously stated, itaconic anhydride can form polymeric structures via radical polymerization or by condensation with other monomers like 
methacrylate-terminated poly-(L-lactic acid) (PLLA) and others. ${ }^{40}$ Compared to maleic anhydride, poly(itaconic anhydride) copolymers are more reactive and can be manufactured by cost effective and more environmentally benign procedures, starting from renewable sources instead of the petrochemical industry, with a molecular weight ranging from $31.95 \mathrm{kDa}$ to $69.60 \mathrm{kDa}$ depending on the original composition. ${ }^{41}$ Such polymers can be conjugated to hyaluronic acid to yield biocompatible gels with properties (thermal stability, swelling behavior, drug loading) differing according to the ratio of the comonomers. ${ }^{42}$

\section{8- Maleic anhydride, itself, its derivatives and (co)polymers derivated thereof} Maleic anhydride differs from succinic anhydride by the presence of a double bond in cis-configuration, so while reactivity towards nucleophiles is the same for the two compounds, maleic derivatives are also prone to Michael-like additions on the double bond or oxidation of the latter. In addition, modification of a biomolecule with maleic anhydride can be easily quantified by absorbance measurements below $280 \mathrm{~nm}$, since the presence of the newly added double bond increases absorbance at those wavelengths.

\section{8-1- $p H$ sensitivity}

Between the various $\mathrm{pH}$-sensitive bonds discovered up to now, ${ }^{43}$ maleic acid amides have become very popular in drug delivery because they are stable at $\mathrm{pH}$ 7.4 but can rapidly be hydrolyzed as the $\mathrm{pH}$ decreases. The reason for this lability has been identified in the cis configuration of the two carbonyle functions. At mildly low $\mathrm{pH}$, the free carboxylate in the $\beta$ position can attack the amide, leading 
to the (re)formation of the corresponding anhydride and the release of the amine counterpart (Scheme 8). The structure of maleic anhydride has been studied to document the influence of substituents on the double bond so as to fine-tune its response to $\mathrm{pH}$ change. In particular, maleamides are stable at neutral $\mathrm{pH}$, but cleave at $\mathrm{pH} 3.5,{ }^{44}$ which increases the importance of using a buffered or alkaline medium for the acylation reaction. So far, maleic, citraconic, cis-aconitic, 2-(2'carboxyethyl)maleic and 1-methyl-2-(2'-carboxyethyl) maleic anhydrides have been compared. ${ }^{9}$ While all five anhydrides show pH-sensibility to some extent, the last three compounds possess an extra carboxylic acid function that is very useful to link another reactive group like an amine. They are therefore interesting linkers for polymodal drug delivery systems or modified polymers.

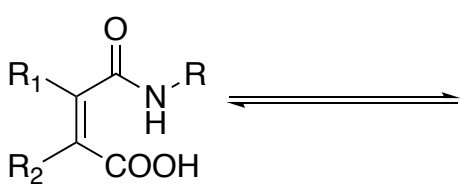<smiles>[R]NC1(O)OC(=O)C([R])=C1[R]</smiles>

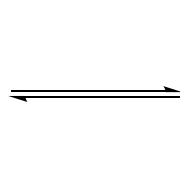<smiles>[R]C1=C([R])C([O-])([O-])OC1=O</smiles><smiles>CCCCCCCC</smiles><smiles>[R]C1=C([R])C(=O)OC1=O</smiles>

Scheme 8: hydrolysis of maleamides at acidic $\mathrm{pH}^{44}$

Maleic and cis-aconitic anhydrides have been used as $\mathrm{pH}$-sensitive linkers to functionalize glass surfaces for repairing bone defects. ${ }^{45}$ In that study, efficiency of the drug-releasing biomaterial was determined by using cysteamine and 5aminofluorescein as probes. Conjugation of anhydrides to the glass surface has been detected by Raman spectroscopy. Using this technique it is possible to distinguish the compounds from each other by observing the characteristic bands for this family of compounds: at $\approx 1850 \mathrm{~cm}^{-1}$ are the stretching vibrations of the carbonyl groups in the cyclic state, this distinctive band is no longer observed when the anhydride has reacted and the ring has opened; instead, bands at 1650 
and $1600 \mathrm{~cm}^{-1}$ are found for the carbonyl group stretching vibrations of, respectively, the carboxylic acid and amide. In this work, a total release of the amine was observed at $\mathrm{pH} 4.5$, while a slow release could be detected at $\mathrm{pH} 7.4$, opening the way to smart materials able to release doxorubicin for the therapy of osteosarcoma.

Polylysine polymers could also benefit from protection by maleic anhydride to obtain a charge reversal. ${ }^{46}$ In that case, side amines were selectively deprotected at $\mathrm{pH}$ 6.5, leading to the cell internalization in tumor tissue of the liposomes they cover, and thus the selective liberation of some active NO by a donor.

Poly(vinyl alcohol) can be crosslinked by maleic anhydride to afford waterinsoluble hydrogel films, with the ability to change the 3-D structure when the surrounding $\mathrm{pH}$ is modified. ${ }^{47}$ The most dramatic changes occur at $\mathrm{pH}$ range $2-7$, and permeability of the gel to hydrophilic molecules such as glucose increases concomitantly.

\section{8-2-Fumaric acid toward maleamic acid}

Isomerisation of fumaramic acid derivatives to maleamic acid ones can be easily achieved by UV irradiation. ${ }^{48}$ Fumaric acid, the trans isomer of maleic acid, forms amides that are not $\mathrm{pH}$-sensitive, because the $\alpha, \beta$-unsaturated carboxylate in this case is not able to attack the amide due to the blocked configuration. The amide is then "locked" and stable at the physiological range of $\mathrm{pH}$. After photoisomerisation at $365 \mathrm{~nm}$, however, maleamic acid derivatives are obtained, and the resulting adduct is "unlocked" and the amine can be delivered again at low pH. This cis-trans isomerization is irreversible; the two species do not seem to reach equilibrium during exposition at $365 \mathrm{~nm}$. The kinetics of the reaction is 
of first order and is faster at $\mathrm{pH} 3$ than at $\mathrm{pH} 7.4$ for fumaramic acid, but can be accelerated and shifted to higher pH (up to 4.5) when bulky substituents on C-3 are present, such as phenyl groups. A drug containing an amino group can thus be effectively uncaged in two steps, first by irradiation, then by exposition to a relatively low $\mathrm{pH}$.

\section{8-3- The formation of maleimides and their interest}

Reaction of maleic anhydride with ammonia and primary amines can lead to maleimides, which are widely used for Michael addition of thiols or other nucleophiles onto the double bond. In principle, maleic anhydride can also act as substrate for this type of addition. ${ }^{49}$

\section{8-4-Maleic anhydride-derived copolymers}

Another important characteristic of maleic anhydride and its derivatives is the reactivity of the double bond, which easily leads to copolymerization. Copolymers able to link amines in a pH-dependent way are thus conveniently prepared.

In this context, low molecular weight (Mw, $5500 \mathrm{Da})$ poly(styrene-alt-maleic anhydride) (Figure 2) has been extensively studied as promising intracellular delivery carrier (such copolymers are often indicated under the generic PSMA acronym, for the random and alternate forms). ${ }^{50}$ The main advantage of this polymer is its easy, metal free synthesis, which is also cost effective and suitable to large-scale manufacturing. Moreover, additional advantages are 1) the easy derivatization of the anhydride blocks, 2) its good solubility in slightly alkaline solution, that may accelerate its elimination from the body and 3) its amphiphilic character, with the aromatic moiety that can interconnect with hydrophobic 
compounds via $\pi$-stacking interactions. In addition with their ability to selfassemble, these numerous advantages make polystyrene-maleic anhydride copolymers a material of choice for the formulation of surfactant-free micelles. Those are often as dual responsive systems in which co-delivery of a hydrophobic drug and a second therapeutic element, such as siRNA, is made possible by both the hydrophobic interactions and the pH-responsive binding with the anhydride moiety. To bind an active substance to a supramolecular drug delivery system, nanoparticles based on poly(styrene-co-maleic anhydride) have for example been used to release paclitaxel at low $\mathrm{pH} .{ }^{51}$ This time, maleic anhydride forms an ester bond with paclitaxel using EDCI after anhydride hydrolysis, and the resulting conjugate shows a pH-sensitive behavior and sustained release over 12 days. Poly(styrene-co-maleic anhydride) has also been used to link multicolored polymeric dots to antibodies for a specific subcellular labeling, ${ }^{52}$ and to prepare dye-doped nanoparticles for bioimaging. ${ }^{53}$

Styrene and maleic anhydride were also at the core of polyampholites or dendrimers in which they were linked to $80 \%$ butylamide terminated poly(amidoamine) and which behaved as protein mimics. ${ }^{54}$ Another useful application of this type of polymer is found in analytical chemistry, giving a method of microextraction and preconcentration of analytes prior to their analysis by HPLC. 55 


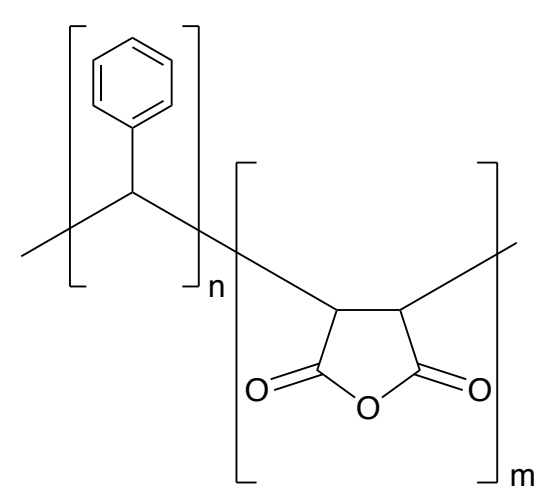

poly(styrene-co-maleic anhydride)

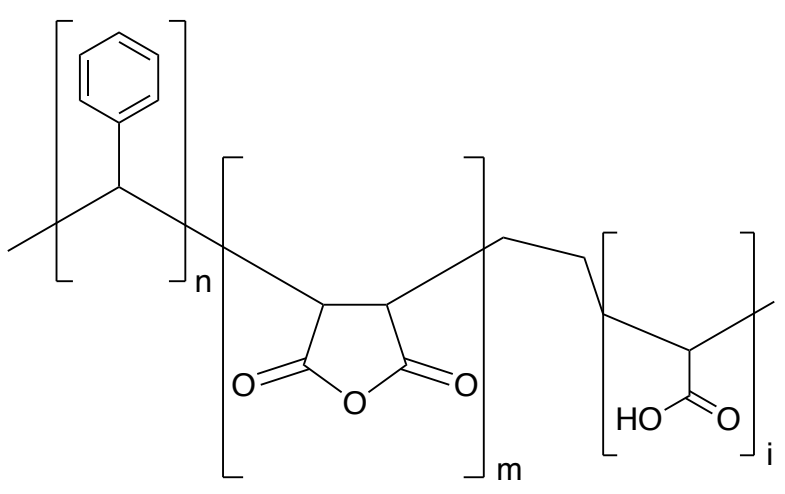

poly(styrene-co-maleic anhydride-acrylic acid)

Figure 2: maleic anhydride-based copolymers.

Poly(styrene-co-maleic anhydride-acrylic acid) (Figure 2) has been used to prepare porous membranes that can bind to an enzyme and act as enzyme reactor. ${ }^{56} \mathrm{~A}$ copolymer with pluronic (also known as poloxamers, triblock PEOPPO-PEO copolymers of hydrophilic poly(ethylene oxide) (PEO) and hydrophobic poly(propylene oxide (PPO)) has been synthetized and characterized to obtain temperature-sensitive hydrogels. ${ }^{57}$ PSMA copolymer could also be blended with polyethersulfone to prepare hollow fiber membranes. ${ }^{58}$ The same concept was used with a poly(acrylonitrile-co-maleic anhydride) ${ }^{59}$ and poly(methylmethacrylate-co-maleic anhydride). ${ }^{60}$ Polystyrene and 4-tert-butylstyrene alternating polymers with maleic anhydride were conjugated with methoxy polyethyleneglycol of different molecular weight, resulting in amphiphilic copolymers that exhibit lower critical solution temperatures, sensitive to $\mathrm{pH}$ and salinity variations and to the presence of hydrophobic or hydrogen-bonding interactions. ${ }^{61}$ The use of maleic anhydridealt-methyl vinyl ether (MAMVE) copolymer has been described for grafting proteins bearing a lysine tag. ${ }^{62}$ Divinylether and maleic anhydride copolymer was also studied for bioconjugation of tumor necrosis factor- $\alpha .63$ 
In addition, a new copolymer composed by maleic anhydride and 3,9-divinyl2,4,8,10-tetraoxaspiro(5.5)undecane was used as a drug carrier system. Part of the maleic anhydride groups were linked to erythritol, used both as a multifunction building block and for its antioxidant properties. ${ }^{64}$

In carbohydrates, modification of curdlan with maleic anhydride was performed to make this polymer pH-sensitive and to exploit maleimide double bond for polymerization with $\mathrm{N}$-isopropylacrylamide. ${ }^{65}$ The resulting material was used to form microparticles displaying a temperature- and $\mathrm{pH}$-sensitive behavior. Chitosan-maleic anhydride copolymers have also been studied. Comb-shaped copolymers containing also polyethylene glycol were used to release coenzyme A in a controlled manner. ${ }^{66}$

Maleic and succinic anhydrides have been used to functionalize several polymers in order to form hydrogels. For example, a chitosan-based copolymer was modified using dimethylmaleic anhydride as a crosslinker for conjugation of doxorubicin and its controlled release at mildly acidic pH. ${ }^{67}$ Another example is the derivatization of inulin ${ }^{6}$ to produce a $\mathrm{pH}$-sensitive hydrogel after UV irradiation, which was stable at gastric $\mathrm{pH}$ but could be degraded in the colon. Interestingly, inulin and succinic anhydride were also used to link to vitamin E. ${ }^{69}$ Another hydrogel composed by dextran-maleic anhydride and Nisopropylarylamide was formed in a DMF/water mixture. The ratio of the two solvents has an influence on this porous network system, on the temperature and pH-response and on the swelling behavior. ${ }^{70}$ 
More recently, the use of hydrogels based on poly(glycidyl methacrylate-comaleic anhydride) has been reported as a $\mathrm{pH}$-sensitive swelling drug delivery system, in this case cefotaxime was used as model drug. ${ }^{71}$

A combined chemo and phototherapy was achieved with systems composed of both PEG-PLL-(-g-Ce6) and PEG-PLL-(g-DMA)-PLA 72 (a dimethylmaleic anhydride copolymer) and with gold nanoclusters. ${ }^{73}$ These particles delivered at the same time photosensitizer chlorin e6 (Ce6) and doxorubicin.

Attractively, cyclodextrins (CD) could also be modified by maleic anhydride to form a copolymer with $N$-isopropylacrylamide ${ }^{74}$ by radical polymerization. The resulting hydrogel is both $\mathrm{pH}^{-}$and temperature-sensitive. This system was effective in the controlled release of naproxen in simulated stomach conditions. ${ }^{75}$ In another example, ${ }^{76} \mathrm{CD}$ modified with maleic anhydride copolymerized with acrylic acid, leading to the formation of a hydrogel with an inclusion potential and a pH-sensitivity.

\section{9- Citraconic anhydride}

2-methylmaleic anhydride, most commonly known as citraconic anhydride, shows a higher sensibility to $\mathrm{pH}$ than maleic anhydride, its amide derivatives being already hydrolyzed at $\mathrm{pH} 3-4$. It is often used for the protection of amine groups during derivatization of proteins with other reagents. The main drawback is its toxicity. ${ }^{1}$

An aspect which is often underestimated with this anhydride is the fact that its reaction with an amine can lead to two regioisomers that may have different hydrolysis profiles, ${ }^{77,78}$ without the possibility of controlling the selectivity. In reality, $\alpha-\mathrm{CH}_{3}$ isomer is the thermodynamic product, favored at high 
temperatures and long reaction times, while $\beta-\mathrm{CH}_{3}$ is the kinetic product, favored by low temperatures, but isomerizing to the $\alpha-\mathrm{CH}_{3}$ when the temperature rises (Scheme 9). More tellingly, studies of the addition of n-butyl amine with citraconic anhydride at different temperatures $\left(0^{\circ} \mathrm{C}, 15^{\circ} \mathrm{C}\right.$ and $\left.30^{\circ} \mathrm{C}\right)$ showed that a complete conversion is reached within 10 min at every temperature, yielding a majority of the kinetic product (58-69\%) regardless of the temperature. This percentage lowers after $48 \mathrm{~h}$ and becomes very slow at $0^{\circ} \mathrm{C}$, where $64 \%$ of the resulting product is still the $\beta-\mathrm{CH}_{3}$ isomer, but dramatically decreases at 15 and $30^{\circ} \mathrm{C}$, where only $20 \%$ and $7 \%$ of the kinetic adduct are respectively detected after $48 \mathrm{~h}$. No Michael addition side-products were found in the crude mixture. ${ }^{79}$

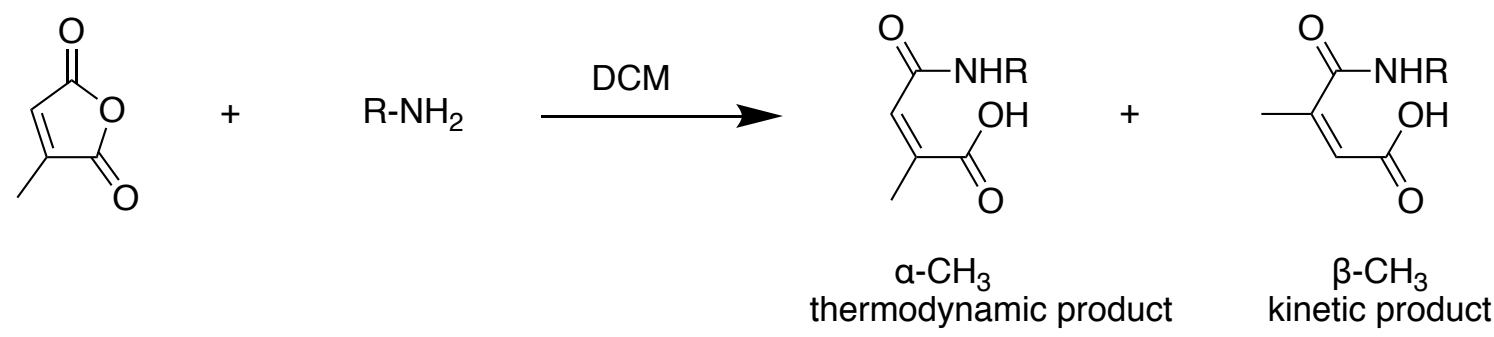

Scheme 9: the two amides obtained when opening citraconic anhydride ring with a primary amine..$^{77,78}$

When citraconic anhydride is added to a positively charged polymer such as poly(2-(3-aminopropyl- $N, N$-dimethylammonium) ethyl methacrylate), the resulting material is zwitterionic at $\mathrm{pH} 7.4$, granting a good biocompatility and low hemotoxicity, but a lower $\mathrm{pH}$ reverses its overall charge to positive. The switch increases the capability of the polymer to bind to bacteria and thus to inhibit their growth, particularly in the case of Escherichia coli and Staphylococcus aureus. $^{80}$ Another application is the $\mathrm{pH}$-sensitive coating on quantum dots with charge reversal ${ }^{81}$ and in a PEI siRNA vector, 82 as well as in a PEG nanoparticle. ${ }^{83}$ 
A nanomicelle based on chitosan, citraconic anhydride and quercetin showed Pgp inhibition and $\mathrm{pH}$ responsiveness. ${ }^{84}$ Another example of a nanogel in which chitosan and citraconic anhydride-modified chitosan were chosen as polyelectrolytes of opposite charges and of different sizes has been reported. ${ }^{85}$ Polyamidoamine dendrimers have also been functionalized by citraconic anhydride, 86 as well as polymeric nanoparticles based on poly(allylamine)-citraconic anhydride-doxorubicin which were used as models of release at lower $\mathrm{pH}^{87}$

Caged phospholipids have been prepared by N-acylation of phosphatidylserine and phosphatidylethanolamine with maleic, citraconic, dimethylmaleic, phthalic and 3,4,5,6-tetrahydrophthalic anhydrides. ${ }^{88}$ The compounds that proved to be more sensitive to $\mathrm{pH}$ variations were citraconic derivatives, especially for the dioleoyl lipids: in that case, after incubation at $\mathrm{pH}$ between 5.5 and $6.5,50 \%$ of hydrolysis were observed within $60 \mathrm{~min}$, with phosphatidylethanolamine derivative being more stable than its serine analogue (110 min half-life versus 85 min respectively). Phthalic and maleic anhydride derivatives did not show significant cleavage at $\mathrm{pH}$ 5.5-8, and tetrahydrophthalic and dimethylmaleic anhydride derivatives were not isolated, as result of their strong instability even at $\mathrm{pH}$ 7.4. Caged lipids are interesting for their use as probes in the study of transmembrane phenomena like aminophospholipid transport, protein-lipid interactions and membrane fusion. ${ }^{89}$

Finally, citraconic and dimethylmaleic anhydrides were used to modify collagen, conferring an increased thermal stability and improved adhesion to tissues, giving the opportunity to use these adducts as wound dressings in tissue engineering. ${ }^{90}$ 


\section{0-Dimethylmaleic anhydride (DMMA or DMA)}

With its double substitution at the double bond, dimethyl maleic anhydride does not display regioselectivity issues, but a reaction with an amine usually results in a mixture of maleamic acid and maleimide. In the latter case, the cyclisation may be due to the steric hindrance and the mutual repulsion of the two methyl groups. The tendency to cyclization is a serious obstacle for purification of the maleamic acid. ${ }^{91,92} \mathrm{~A}$ systematic study of the reaction between dimethylmaleic anhydride and $n$-butylamine with different parameters such as solvents, catalyst and temperature showed that maleamic acid is favored in polar solvents, likewise DMF, more basic catalysts, as TEA, and low temperature $\left(0^{\circ} \mathrm{C}\right)$. The molar ratio of TEA/anhydride has to be 2 or more in order to have a $100 \%$ conversion in $4 \mathrm{~h} .{ }^{79}$ Various smart delivery systems based on the lability of the amide at tumoral $\mathrm{pH}$ have been developed..$^{93}$ Thus, micelles based on self-assembly of poly(lysine-co$\mathrm{N}, \mathrm{N}$-bis(acryloyl) cystamine-co-dimethylmaleic anhydride have been prepared. ${ }^{94}$ Their surface has an overall negative charge under physiological $\mathrm{pH}$, and undergoes a charge switch to positive values when exposed to the tumor environment. After internalization into the cell, endosomal escape is facilitated by a proton-sponge effect, and delivery of the cargo is triggered by reduction of the disulfide bridges of the polymer chains.

Methoxy poly(ethylene glycol)-block-poly(L-lysine) was modified with different anhydrides to modulate its response to $\mathrm{pH}$ variations in micellar formulations. ${ }^{95}$ The anhydrides used were succinic, cis-cyclohexene-1,2-dicarboxylic, cis-aconitic, and, more importantly, dimethylmaleic anhydride. Gradient $\mathrm{pH}$ sensitivity was greater for dimethylmaleic anhydride and lesser for succinic anhydride. 
2,3-dimethylmaleic anhydride was used as linker to a cell penetrating peptidebased nanoparticle. ${ }^{96} \mathrm{~A}$ tat peptide enriched with two lysine residues was linked to the anhydride, blocking its entry into cells by masking the positive charges. At acidic $\mathrm{pH}$, charge reversal could enhance cell penetration and release of the cargo. The same strategy was used for chitosan, ${ }^{97}$ and modified chitosan could also be used as coating to graphene oxide nanoparticles. ${ }^{98}$

DMMA was also used to functionalize a poly(2-diisopropylaminoethyl methacrylate)-block-poly(2-aminomethyl hydrochloride) to form nanomicelles with dual pH-sensitivity. ${ }^{99}$ In addition, polyethyleneimine was coupled with dimethylmaleic anhydride to obtain a zwitterionic polymer at physiological $\mathrm{pH}$, thus avoiding cytotoxicity, which is normally due to the positive charge. ${ }^{100} \mathrm{~A}$ similar strategy was reported by protecting polylysine with dimethylmaleic anhydride. ${ }^{101}$ Interestingly, poly(vinylpyrrolidone-co-dimethylmaleic anhydride) was developed to link adriamycine at $\mathrm{pH} 8.5$ then release it gradually at lower $\mathrm{pH}$, such as 7.0 and 6.0.102

\section{1-Cis-aconitic anhydride}

The pH sensitivity of cis-aconitic anhydride renders this compound especially useful as a cleavable ligand for passive targeting purposes, and, more importantly, it is the simplest anhydride bearing an extra carboxylate function that can be used to anchor amines and keep the anhydride group free. On the other hand, side-reactions are often observed during amide formation with this anhydride, principally by formation of allyl-shifted isomers or itaconic acid derivatives (Scheme 10). ${ }^{103}$ These side-products do not show any pH-sensitivity, thus homologous carboxylated anhydrides i.e. with one or two additional 
methylene $\operatorname{link}(\mathrm{s})$ in the side chain (like 2-(2'-carboxyethyl)maleic anhydride or 1-methyl-2-(2'-carboxyethyl) maleic anhydride, Figure 1) are currently preferred.

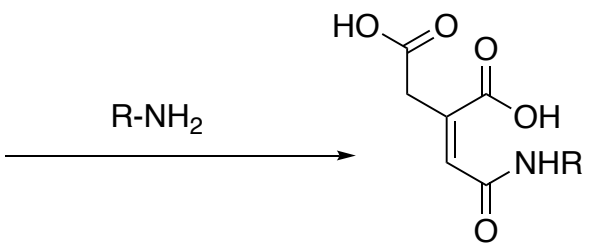<smiles>O=C(O)CC1=CC(=O)OC1=O</smiles>

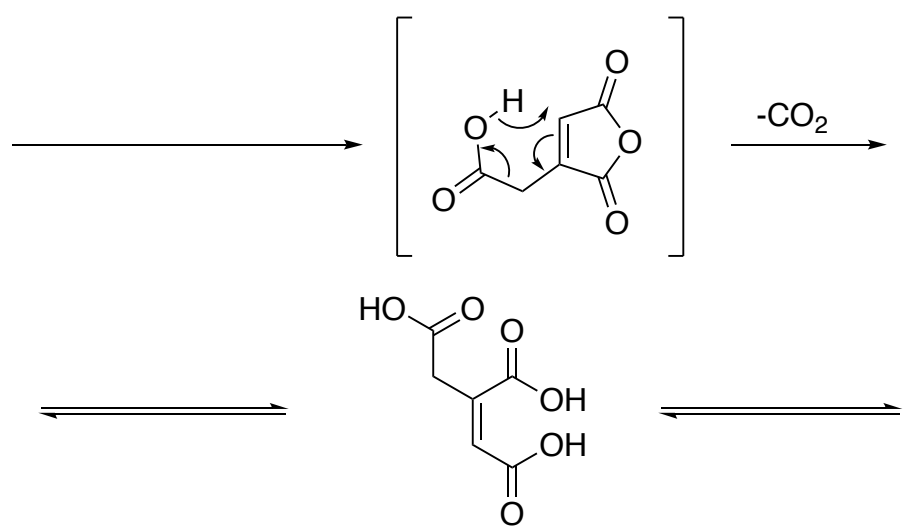<smiles>C=C1CC(=O)OC1=O</smiles><smiles>O=C(O)C=C(CC(=O)O)C(=O)O</smiles>

Scheme 10: formation of allyl-shifted isomers or itaconic acid derivatives when opening cis-aconitic anhydride with a primary amine..$^{103}$

Numerous examples of use of cis-aconitic anhydride are nonetheless reported. The first report of the use of this anhydride to build a linker between an anthracycline, like daunomycin, and a macromolecule has been published by Shen et al. ${ }^{104}$ and is still the method of choice for this type of coupling. In this case, the amino group of the drug reacts with the anhydride, then one of the available carboxylic groups can react with the macromolecule with the help of a coupling agent, like a carbodiimide. Further studies showed that the reaction between cis-aconitic anhydride and daunomycin yielded both $E$ and $Z$ isomers, which are easily assigned by ${ }^{1} \mathrm{H}-\mathrm{NMR}$ and HPLC. ${ }^{105}$ The two isomers differ in stability at low $\mathrm{pH}$, the $Z$ compound releasing the drug much faster than the $E$ counterpart. 
Human serum albumin linked to cis-aconitic anhydride was coupled to liposomes to give a targeting effect toward hepatic endothelial cells. ${ }^{106}$ Another example is the binding of doxorubicin to bovine serum albumin (BSA) bearing folate as an active targeting moiety for cancer cells. ${ }^{107}$ The same anhydride was successfully used to link curcumin to pluronic F68 micelles. ${ }^{108}$ It was also used to link doxorubicin to target alpha-fetoprotein receptor 109 and to chitosan nanoparticles, ${ }^{110}$ as well as to PEI nanoparticles for the codelivery of siRNA, ${ }^{111}$ or even for the formation of multilayer films with oxidized alginate as a nonvascular stent coating to ensure bactericidal and long-term release properties. ${ }^{112}$ A magnetic version of chitosan nanoparticles was also studied. ${ }^{113}$ Finally, cisaconitic anhydride was also used for the ligation of antibodies to gold nanoparticles ${ }^{114}$ or to cytotoxic drugs, such as doxorubicin. ${ }^{115}$

Protection of amine groups by cis-aconitic anhydride in peptides, for example by reaction of the $\varepsilon-\mathrm{NH}_{2}$ in lysine, leads to a greater hydrophilicity at $\mathrm{pH} 7.4$, which turns to a greater hydrophobicity at $\mathrm{pH}$ 6.5, and thus to a valuable peptide selfassembly in that case. ${ }^{116}$ Poly(aspartate-diethanolamine) was also functionalized with both succinic and cis-aconitic anhydrides to get a finely tuned chargeconversion at lower pH.117

Photosensitizer chlorin e6 was encapsulated into theranostic nanoparticles composed by D- $\alpha$-tocopheryl polyethylene glycol 1000 succinate linked to cisaconitic anhydride modified doxorubicin. ${ }^{118}$ Advantageously, these bifunctional nanoparticles allowed chemo- and photodynamic therapy simultaneously. Reversible PEGylation is a way to ensure prolonged circulation time of a drug in the blood and greater accumulation in tumor tissue. Doxorubicin could be linked 
to PEG by succinic anhydride (to have a stable micelle at any $\mathrm{pH}$ value) or here also by cis-aconitic anhydride, endowing pH-sensitivity. The latter micelle displays the desired behavior of being stable at $\mathrm{pH} 7.4$, while dissociating at lower $\mathrm{pH}$ starting from 6.8 and completely at $\mathrm{pH} 5.5$, with a successful release of the anticancer drug. ${ }^{119}$ In parallel, micelles of a di-block copolymer composed of PEG and poly(lactic acid) with hydrazone and a cis-aconityl bond with the doxorubicin were compared as $\mathrm{pH}$-sensitive systems. ${ }^{120}$ While the cis-aconityl bond seemed more effective in terms of speed of release of doxorubicin at $\mathrm{pH} 3$ and stability at $\mathrm{pH} 7$ than the hydrazone bond, according to the authors, the drug did not seem to be fully released in its intact form.

In PEGylated polyamidoamine dendrimers, linkage of doxorubicin by cis-aconitic anhydride provided better release of the drug in tumor tissues and an increased activity, even if dendrimers bearing a succinic anhydride linker accumulate even more into the tumor. ${ }^{121}$

Adriamycin previously linked to cis-aconitic anhydride was conjugated to $\mathrm{N}$-(2hydroxypropyl)methacrylamide copolymer via EDCI as a coupling reagent. Drug released after $48 \mathrm{~h}$ incubation at $\mathrm{pH} \mathrm{5,6}$ and 7 was estimated as 63.4, 9.2 and $2.8 \%$ respectively. In vitro, release in pre-lysosome and lysosome was faster than with an enzyme-sensitive conjugate specific for lysosome enzymes. ${ }^{122}$

\section{2-2-propionic-3-methylmaleic anhydride or carboxylate-dimethylmaleic} anhydride (CDA)

In comparison with cis-aconitic anhydride, 2-propionic-3-methylmaleic anhydride amides degrade faster at $\mathrm{pH}$ 5.5, and do not show side-reactions when they react with amines. Thus, this anhydride has rapidly become the most used 
anhydride in the field of smart delivery systems, and has been chosen for some examples of charge-reversal. ${ }^{123}$

A carrier composed of $\beta$-cyclodextrin coupled to 1-methyl-2-(2'carboxyethyl)maleic anhydrides was described. ${ }^{124}$ Anhydrides were linked to the outer primary hydroxyl groups, while the inner part of the CD was used to form host-guest interactions with hydrophobic molecules.

A nanoparticular system called iCluster $^{125}$ prepared by assembling platinum prodrug-conjugated poly(amidoamine)-graft-PCL and PEG- $b$-PCL, is effective in tumor targeting due to its reduced size: in blood circulation, the nanoparticle has a diameter of $100 \mathrm{~nm}$, which is ideal for long circulation times and extravasation by enhanced permeability and retention (EPR) effect. Once in the tumor environment, the amide bond is cleaved, releasing a $5 \mathrm{~nm}$ Pt-coupled nanoparticle, which penetrates more easily in poorly accessible tumor interstices. This system proved to be very effective in pancreatic cancer treatment.

Carboxylate dimethylmaleic anhydride was used to functionalize silica in order to obtain an amine-selective affinity resin, which can selectively bind to aminebearing molecules and easily release them from the support, providing an effective separation from other compounds. ${ }^{126}$

With the same anhydride, crosslinkers based on 8-arm-PEG chains can be used to bind protein particles. ${ }^{127}$ Disassembly at $\mathrm{pH}<6.5$ leads to the release of intact proteins, which keep their functionality, as shown in the case of glucose oxidase. Polymeric particles linking siRNA have been reported, in which CDA was used to link polylysine to a cyclooctyne moiety that has been clicked to an azide-modified RNA. $^{128}$ 
Also, this anhydride has been used to create a water-soluble solid support used for synthesis of polysaccharides. ${ }^{129}$ While the supporting polymer is insoluble in water when the anhydride ring is closed, it becomes soluble as soon as it reacts with the substrate and the ring opens. During the reaction it is thus possible to have the advantageous kinetics of homogeneous phase reactions, while a simple $\mathrm{pH}$ modification can cleave the final product and separate it easily from the support. The same anhydride has been reported in the formation of a doxorubicin pro-drug for charge reversal. ${ }^{130}$

\section{3-Bicyclic anhydrides}

Bicyclic anhydrides are generally less used for bioconjugation purposes, nonetheless some interesting examples can be found in recent literature. We chose to discuss in detail those shown in Figure 3 as they are the most significant ones in terms of application in this field.<smiles>O=C1OC(=O)C2CCCCC12</smiles>

1,2-cis-cyclohexanedicarboxylic anhydride<smiles>O=c1[nH]c2ccccc2c(=O)o1</smiles>

isatoic anhydride<smiles>O=C1OC(=O)c2ccccc21</smiles>

phthalic anhydride<smiles>O=C(O)c1ccc2c(c1)C(=O)OC2=O</smiles>

trimellitic anhydride<smiles>O=C1Cc2ccccc2C(=O)O1</smiles>

homophthalic anhydride<smiles>O=c1oc(=O)c2cc3c(=O)oc(=O)c3cc12</smiles>

pyromellitic dianhydride

Figure 3: principal bicyclic anhydrides. 
Apart from the anhydrides cited in Figure 3, bicyclic $\alpha, \beta$-unsaturated anhydrides are also known and can be used in further reactions. Their synthesis can be realized by Diels-Alder cycloaddition followed by reaction with acetic anhydride (Scheme 11). The anhydride obtained with cyclopentadiene can undergo ethylene extrusion at $110^{\circ} \mathrm{C}$ by Alder-Rickert reaction. ${ }^{131}$ Polymers from bicyclic $\alpha, \beta$-unsaturated anhydrides could be obtained by ring opening metathesis polymerization (ROMP), and the furan ring could be cleaved by $\mathrm{FeCl}_{3}$, as it has an allyl ether structure. ${ }^{132}$
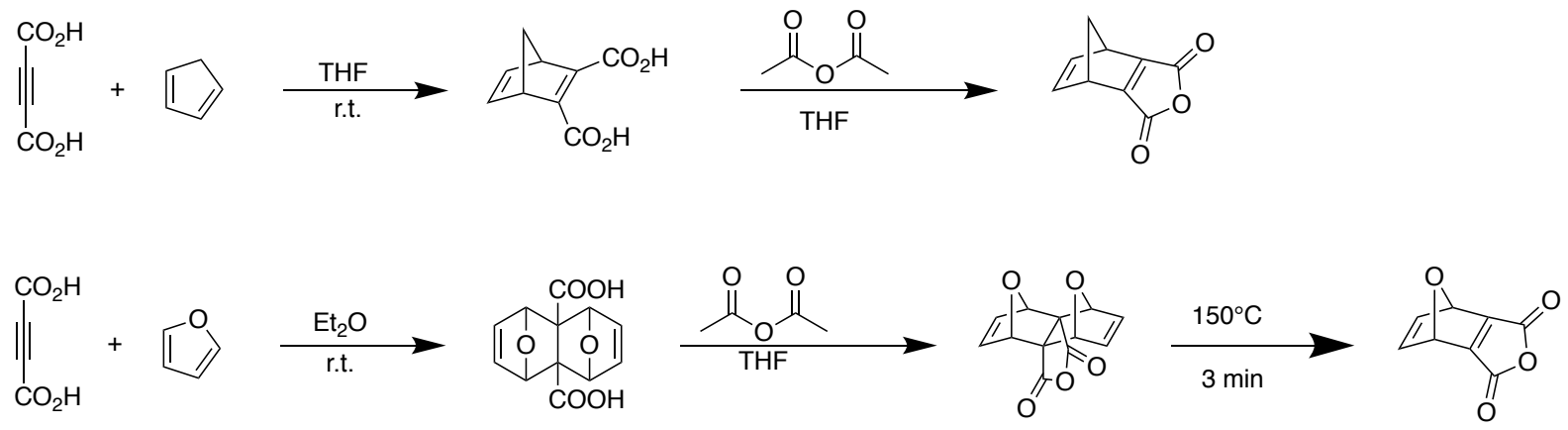

Scheme 11: synthesis of bicyclic $\alpha, \beta$-unsaturated anhydrides by Diels-Alder cycloaddition. ${ }^{132}$

14-1,2-cis-cyclohexanedicarboxylic anhydride (3,4,5,6-tetrahydrophthalic anhydride, THPA)

This hydrophobic anhydride has been used for the formation of $\mathrm{pH}$-sensitive micelles with PEG, ${ }^{133}$ as well as for functionalization of silica shells of magnetic nanoparticles for the delivery of peptides. ${ }^{134,135}$ Poly(glycerol methacrylate) could also be modified by both succinic and 1,2-cyclohexanedicarboxylic anhydride, the latter showing a good response to $\mathrm{pH}$ variations. ${ }^{136} 3,4,5,6$ tetrahydrophthalic anhydride was coupled to polyamidoamine (PAMAM) dendrimers to get $\mathrm{pH}$-sensitive nanoparticles, allowing the dissociation of the 
particles and the subsequent release of all-trans retinoic acid selectively at $\mathrm{pH}$ 6.0 .137

\section{5- Phthalic anhydride}

Phthalic anhydride is commonly used as a starting material for the protection of primary amines and the temporary $\mathrm{N}$-phthalimide can be cleaved by many compounds like hydrazine, hydroxylamine or sodium borohydride ${ }^{138}$. Phthalic anhydride is also a starting compound for the synthesis of Rhodamines, one of the most used families of dyes in chemical biology. Another interesting use of this anhydride is the modification of horseradish peroxidase, which led to the increase of its stability in some organic solvents (DMF, methanol, THF and acetonitrile) without dramatic decrease of its catalytic activity. ${ }^{139}$ It can also be used in the formation of polymers. It has a limited use as linker in bioconjugate chemistry.

\section{6-Homophthalic anhydride}

A very recent example of conjugation of homophthalic anhydride on iminemodified DNA was reported by Yuen et al. ${ }^{140}$ The aim of their work was to obtain isoquinolone-modified DNA that still beared a carboxylic moiety able to link different amines. Further functionalization by benzylamine, aniline, butylamine and piperidine afforded the corresponding amides in $45-85 \%$ yields, allowing a simple preparation of DNA libraries.

\section{7-Isatoic anhydrides}


Ring-fused oxazine-2,4-diones are of interest for synthetic purposes, ${ }^{141}$ but recently, so-called isatoic anhydrides have also been used as tools for bioconjugation. Their water-solubility and the intrinsic chromophore absorbing at wavelengths outside the biological window, thus facilitating their quantification, render them particularly suitable for this type of chemistry. ${ }^{142}$ One of the first platforms was constituted by $N$-(N,N-dimethylaminoethylene) isatoic anhydride (DMIA), which possesses the advantages listed above, combining the electrophilic reactivity of the anhydride with the nucleophilicity of the tertiary amine on the side chain. This last functional group has a limited reactivity, so to broaden the scope of the ligation, other derivatives with a halide, such as $\mathrm{N}$-(3iodopropyl)isatoic anhydride (IPIA), have been developed and successfully used for ligation with lysine side chains of BSA with a controlled degree of labeling, and further for binding RNA for selective 2'-hydroxyl acylation analyzed by primer extension. A green synthesis of this type of anhydrides is also available. ${ }^{143}$

\section{8- Trimellitic anhydride}

Trimellitic anhydride is a tricarboxylic anhydride that can be used to obtain polymers with low coefficients of thermal expansion and low water absorption. ${ }^{144}$ Its use is limited in bioconjugation applications.

\section{9- Pyromellitic dianhydride}

Pyromellitic anhydride (PMDA) is a double anhydride, mostly used in the synthesis of polymers such as Kapton, a polyimide with a wide stability range. Due to its rigidity, this linker is suitable for the construction of two- and threedimensional scaffolds. Covalent organic frameworks of macromolecules could be 
organized in the form of ribbons and reticulated in 2D structures with this molecule. ${ }^{145}$ The use of pyromellitic anhydride was also reported in the assemblage of $\beta$-cyclodextrins-based nanosponges for nitric oxide delivery. ${ }^{146}$ Pyromellitic anhydride can also give dynamic covalent bonds in polyesters. ${ }^{147}$

\section{Conclusion}

This overview of the principal cyclic anhydrides used in bioconjugation shows the numerous advantages of using this class of compounds in a large scope of applications. A good number of synthetic strategies are now available to obtain these compounds easily and in bulk scale, most of them are thus commercially available at low costs. Their use in synthesis, bioconjugate chemistry and chemical biology is simple and requires fewer activators than their diacid counterparts. Most importantly, their use is not limited to the crosslinking between two molecules, thus cyclic anhydrides are also valuable protecting groups for amines. In addition, in large macromolecules or nanoparticles they can be used for charge reversal, allowing their behavior to be tuned to entity to which they are targeted according to the $\mathrm{pH}$ of the milieu. Last but not least, many of these anhydrides and mostly their amide/imide derivatives are $\mathrm{pH}$-sensitive, and the range of $\mathrm{pH}$ is principally dependent on the substituents on the ring. This paves the way to smart delivery systems able to target low $\mathrm{pH}$ tissues selectively. Truly, cyclic anhydrides are compounds of choice in bioconjugation.

\section{Acknowledgments}


We acknowledge our tutelar financing instances, Unistra and CNRS. This work of the Interdisciplinary Thematic Institute InnoVec, as part of the ITI program of the University of Strasbourg, CNRS and Inserm, was supported by IdEx Unistra (ANR10-IDEX-0002), and by SFRI-STRAT'US project (ANR-20-SFRI-0012) under the framework of the French Investments for the Future Program. We thank Dr. Oliver Broom for proofreading the manuscript.

\section{References}

(1) Hermanson, G. T. (2013) Chapter 5 - Homobifunctional Crosslinkers, in Bioconjugate Techniques (Third Edition) pp 275-298, Academic Press, Boston. (2) An, T., Kang, B., Kang, S., Pac, J., Youk, J., Lin, D., and Lee, Y. (2019) Guanidine cyclic diimides and their polymers. Chem. Commun. 55, 10222-10225.

(3) Du, J.-Z., Sun, T.-M., Song, W.-J., Wu, J., and Wang, J. (2010) A tumor-acidityactivated charge-conversional nanogel as an intelligent vehicle for promoted tumoral-cell uptake and drug delivery. Angew. Chem. Int. Ed. 49, 3621-3626.

(4) Robert, C., de Montigny, F., and Thomas, C. M. (2014) Facile and efficient synthesis of cyclic anhydrides from dicarboxylic acids. ACS Catal. 4, 3586-3589. (5) Robert, C., de Montigny, F., and Thomas, C. M. (2011) Tandem synthesis of alternating polyesters from renewable resources. Nat. Commun. 2, 586.

(6) Mason, F. A. (1930) XCI.-A simple method for the preparation of maleic anhydride. J. Chem. Soc. (Resumed), 700-701.

(7) Ozkan, U., and Schrader, G. L. (1985) $\mathrm{NiMoO}_{4}$ selective oxidation catalysts containing excess $\mathrm{MoO}_{3}$ for the conversion of $\mathrm{C} 4$ hydrocarbons to maleic anhydride: III. Selective oxidation of 1,3-butadiene and furan. J. Catal. 95, 147154.

(8) Chatzidimitriou, A., and Bond, J. Q. (2015) Oxidation of levulinic acid for the production of maleic anhydride: breathing new life into biochemicals. Green Chem. 17, 4367-4376.

(9) Kang, S., Kim, Y., Song, Y., Choi, J. U., Park, E., Choi, W., Park, J., and Lee, Y. (2014) Comparison of pH-sensitive degradability of maleic acid amide derivatives. Bioorg. Med. Chem. Lett. 24, 2364-2367.

(10) Mongrain, C., and Gaudreault, R. (1990) Synthesis of mono and disubstituted maleic anhydrides from di-tert-butyl acetylene dicarboxylate. Synthetic Commun. 20, 2491-2500.

(11) Florac, C., Baudy-Floc'h, M., and Robert, A. (1990) Synthese de N-amino maléimides et d'anhydrides maléiques disubstitués à partir d' $\alpha$-halogéno hydrazides. Etude du mécanisme de la réaction. Tetrahedron 46, 445-452.

(12) Ortega-Muñoz, M., Vargas-Navarro, P., Hernandez-Mateo, F., Salinas-Castillo, A., Capitan-Vallvey, L. F., Plesselova, S., Salto-Gonzalez, R., Giron-Gonzalez, M. D., Lopez-Jaramillo, F. J., and Santoyo-Gonzalez, F. (2019) Acid anhydride coated 
carbon nanodots: activated platforms for engineering clicked (bio)nanoconstructs. Nanoscale 11, 7850-7856.

(13) Weder, J. K. P., Belitz, H. D., and Caballero, B. (2003) Protein | Functional properties, in Encyclopedia of Food Sciences and Nutrition (Second Edition) pp 4835-4841, Academic Press, Oxford.

(14) Jansen, R. W., Molema, G., Pauwels, R., Schols, D., De Clercq, E., and Meijer, D. K. (1991) Potent in vitro anti-human immunodeficiency virus-1 activity of modified human serum albumins. Mol. Pharmacol. 39, 818.

(15) Jansen, R. W., Schols, D., Pauwels, R., De Clercq, E., and Meijer, D. K. (1993)

Novel, negatively charged, human serum albumins display potent and selective in vitro anti-human immunodeficiency virus type 1 activity. Mol. Pharmacol. 44, 1003.

(16) Schoen, P., Corver, J., Meijer, D. K. F., Wilschut, J., and Swart, P. J. (1997) Inhibition of influenza virus fusion by polyanionic proteins. Biochem. Pharmacol. $53,995-1003$.

(17) Gounaris, A. D., and Perlmann, G. E. (1967) Succinylation of pepsinogen. J. Biol. Chem. 242, 2739-2745.

(18) Matteucci, M. D., and Caruthers, M. H. (1981) Synthesis of deoxyoligonucleotides on a polymer support. J. Am. Chem. Soc. 103, 3185-3191. (19) Tadayoni, B. M., Friden, P. M., Walus, L. R., and Musso, G. F. (1993) Synthesis, in vitro kinetics, and in vivo studies on protein conjugates of AZT: evaluation as a transport system to increase brain delivery. Bioconjugate Chem. 4, 139-145. (20) Dong, D.-W., Tong, S.-W., and Qi, X.-R. (2013) Comparative studies of polyethylenimine-doxorubicin conjugates with $\mathrm{pH}$-sensitive and $\mathrm{pH}$-insensitive linkers. J. Biomed. Mater. Res. A 101A, 1336-1344.

(21) Sun, X., Jiang, G., Wang, Y., and Xu, Y. (2011) Synthesis and drug release properties of novel $\mathrm{pH}$ - and temperature-sensitive copolymers based on a hyperbranched polyether core. Colloid Polym. Sci. 289, 677-684.

(22) Wilbur, D. S., Hamlin, D. K., Meyer, D. L., Mallett, R. W., Quinn, J., Vessella, R. L., and Press, O. W. (2002) Streptavidin in antibody pretargeting. 3. Comparison of biotin binding and tissue localization of 1,2-cyclohexanedione and succinic anhydride modified recombinant streptavidin. Bioconjugate Chem. 13, 611-620. (23) Xu, P., Bajaj, G., Shugg, T., Van Alstine, W. G., and Yeo, Y. (2010) Zwitterionic chitosan derivatives for $\mathrm{pH}$-sensitive stealth coating. Biomacromolecules 11, 2352-2358.

(24) Tamaki, M., Fukushima, D., and Kojima, C. (2018) Dual pH-sensitive and UCST-type thermosensitive dendrimers: phenylalanine-modified polyamidoamine dendrimers with carboxyl termini. RSC Adv. 8, 28147-28151. (25) Giannuzzo, M., Feeney, M., Paolicelli, P., and Casadei, M. A. (2006) Synthesis and characterization of $\mathrm{pH}$-sensitive hydrogels of dextran. J. Drug Deliv. Sci. Tec. $16,49-54$.

(26) Giannuzzo, M., Corrente, F., Feeney, M., Paoletti, L., Paolicelli, P., Tita, B., Vitali, F., and Casadei, M. A. (2008) pH-Sensitive hydrogels of dextran: Synthesis, characterization and in vivo studies. J. Drug Target. 16, 649-659..

(27) Yu, Z., Ma, L., Ye, S., Li, G., and Zhang, M. (2020) Construction of an environmentally friendly octenylsuccinic anhydride modified $\mathrm{pH}$-sensitive chitosan nanoparticle drug delivery system to alleviate inflammation and oxidative stress. Carbohyd. Polym. 236, 115972. 
(28) Klotz, I. M., and Heiney, R. E. (1962) Introduction of sulfhydryl groups into proteins using acetylmercaptosuccinic anhydride. Arch. Biochem. Biophys. 96, 605-612.

(29) Klotz, I. M., and Heiney, R. E. (1959) A new method for the introduction of thiol groups into proteins. J. Am. Chem. Soc. 81, 3802-3803.

(30) Meng-Yan, Y., and Pilcher, G. (1990) Enthalpies of combustion of succinic anhydride, glutaric anhydride, and glutarimide. J. Chem. Thermodyn. 22, 893-898.

(31) Gandhi, S. K., Schultz, J. R., Boughey, F. W., and Forsythe, R. H. (1968)

Chemical modification of egg white with 3, 3-dimethylglutaric anhydride. J. Food

Sci. 33, 163-169.

(32) Kao, K.-C., Lee, C.-H., Lin, T.-S., and Mou, C.-Y. (2010) Cytochrome c covalently immobilized on mesoporous silicas as a peroxidase: Orientation effect. J. Mater. Chem. 20, 4653-4662.

(33) Yuba, E., Tajima, N., Yoshizaki, Y., Harada, A., Hayashi, H., and Kono, K. (2014) Dextran derivative-based $\mathrm{pH}$-sensitive liposomes for cancer immunotherapy.

Biomaterials 35, 3091-3101.

(34) Sakaguchi, N., Kojima, C., Harada, A., and Kono, K. (2008) Preparation of pHsensitive poly(glycidol) derivatives with varying hydrophobicities: their ability to sensitize stable liposomes to pH. Bioconjugate Chem. 19, 1040-1048.

(35) Liu, H., Kar, N., and Edgar, K. J. (2012) Direct synthesis of cellulose adipate derivatives using adipic anhydride. Cellulose 19, 1279-1293.

(36) Ramos-Tomillero, I., Pérez-Chacon, G., Somovilla-Crespo, B., Sánchez-Madrid, F., Cuevas, C., Zapata, J. M., Domínguez, J. M., Rodríguez, H., and Albericio, F. (2020) From Ugi multicomponent reaction to linkers for bioconjugation. ACS Omega 5, 7424-7431.

(37) Wu, Y., Sun, N., and Deng, C. (2020) Construction of magnetic covalent organic frameworks with inherent hydrophilicity for efficiently enriching endogenous glycopeptides in human saliva. ACS Appl. Mater. Inter. 12, 9814-9823. (38) Galanti, M. C., and Galanti, A. V. (1981) Kinetic study of the isomerization of itaconic anhydride to citraconic anhydride. J. Org. Chem. 47, 1572-1574. (39) Palai, T., Kumar, A., and Bhattacharya, P. K. (2014) Synthesis and characterization of thermo-responsive poly- $\mathrm{N}$-isopropylacrylamide bioconjugates for application in the formation of galacto-oligosaccharides. Enzyme Microb. Tech. 55, 40-49. (40) Nagai, S. (1964) The polymerization and polymers of itaconic acid derivatives. VI. The polymerization and copolymerization of itaconic anhydride. Bull. Chem. Soc. Jap. 37, 369-373.

(41) Diaconu, A., Chiriac, A. P., Nita, L. E., Tudorachi, N., Neamtu, I., Vasile, C., and Pinteala, M. (2015) Design and synthesis of a new polymer network containing pendant spiroacetal moieties. Des. Monomers Polym. 18, 780-788.

(42) Chiriac, A. P., Nita, L. E., Diaconu, A., Bercea, M., Tudorachi, N., Pamfil, D., and Mititelu-Tartau, L. (2017) Hybrid gels by conjugation of hyaluronic acid with poly(itaconic anhydride-co-3,9-divinyl-2,4,8,10-tetraoxaspiro (5.5)undecane) copolymers. Int. J. Biol. Macromol. 98, 407-418.

(43) Deirram, N., Zhang, C., Kermaniyan, S. S., Johnston, A. P. R., and Such, G. K. (2019) pH-responsive polymer nanoparticles for drug delivery. Macromol. Rapid Comm. 40, 1800917. 
(44) Butler, P. J., Harris, J. I., Hartley, B. S., and Leberman, R. (1967) Reversible blocking of peptide amino groups by maleic anhydride. Biochem. J. 103, 78P-79P. (45) Aina, V., Magistris, C., Cerrato, G., Martra, G., Viscardi, G., Lusvardi, G., Malavasi, G., and Menabue, L. (2014) New formulation of functionalized bioactive glasses to be used as carriers for the development of $\mathrm{pH}$-stimuli responsive biomaterials for bone diseases. Langmuir 30, 4703-4715.

(46) Chen, M., Song, F., Liu, Y., Tian, J., Liu, C., Li, R., and Zhang, Q. (2019) A dual $\mathrm{pH}$-sensitive liposomal system with charge-reversal and NO generation for overcoming multidrug resistance in cancer. Nanoscale 11, 3814-3826.

(47) Liou, F. J., and Wang, Y. J. (1996) Preparation and characterization of crosslinked and heat-treated PVA-MA films. J. Appl. Polym. Sci. 59, 1395-1403. (48) Choi, W., Kang, S., Mok, Y., Park, E., Song, Y., Choi, S. J., and Lee, Y. (2014) Unlocking the pH-responsive degradability of fumaramic acid derivatives using photoisomerisation. Chem. Eur. J. 20, 15715-15718.

(49) Gurjar, A., Sinha, P., and Bansal, R. K. (2014) Tandem Michael addition of amines to maleic anhydride and 1,3-prototropic shift: experimental and theoretical results. Tetrahedron 70, 5052-5056.

(50) Aji Alex, M. R., Nehate, C., Veeranarayanan, S., Kumar, D. S., Kulshreshtha, R., and Koul, V. (2017) Self assembled dual responsive micelles stabilized with protein for co-delivery of drug and siRNA in cancer therapy. Biomaterials 133, 94106.

(51) Dalela, M., Shrivastav, T. G., Kharbanda, S., and Singh, H. (2015) pH-sensitive biocompatible nanoparticles of paclitaxel-conjugated poly(styrene-co-maleic acid) for anticancer drug delivery in solid tumors of syngeneic mice. ACS Appl. Mater. Inter. 7, 26530-26548.

(52) Wang, D., Liu, J., Liu, Z., Zhang, Z., Sun, Z., Wu, C., and Wang, G. (2020) Bioconjugation of IgG secondary antibodies to polymer dots for multicolor subcellular imaging. ACS Applied Nano Materials 3, 2214-2220.

(53) Swanepoel, A., du Preez, I., Mahlangu, T., Chetty, A., and Klumperman, B. (2015) Development of bioconjugated dye-doped poly(styrene-co-maleimide) nanoparticles as a new bioprobe. J. Mater. Chem. B 3, 2635-2640.

(54) Xia, Y., Gao, M., Chen, Y., Jia, X., and Liang, D. (2011) Mimic of protein: a highly $\mathrm{pH}$-sensitive and thermoresponsive polyampholyte. Macromol. Chem. Phys. 212, 2268-2274.

(55) González-Martín, R., Pacheco-Fernández, I., Maiti, B., Ayala, J. H., Afonso, A. M., Díaz, D. D., and Pino, V. (2020) Use of a pH-sensitive polymer in a microextraction and preconcentration method directly combined with highperformance liquid chromatography. J. Chromatogr. A, 1619, 460910.

(56) Qiao, J., Jiang, J., Liu, L., Shen, J., and Qi, L. (2019) Enzyme reactor based on reversible ph-controlled catalytic polymer porous membrane. ACS Appl. Mater. Inter. 11, 15133-15140.

(57) Xi, H., Yang, L., and Chen, J. (2013) Synthesis and characterization of pH- and temperature-sensitive hydrogels of poly (styrene-alt-maleic anhydride)-copluronic for drug release. J. Macromol. Sci. B 52, 1198-1211.

(58) Xiang, T., Tang, M., Liu, Y., Li, H., Li, L., Cao, W., Sun, S., and Zhao, C. (2012) Preparation and characterization of modified polyethersulfone hollow fiber membranes by blending poly (styrene-alt-maleic anhydride). Desalination 295, 26-34. 
(59) Xiang, T., Fu, H., Yue, W.-W., Sun, S.-D., and Zhao, C.-S. (2013) Preparation and characterization of poly(acrylonitrile-co-maleic anhydride) copolymer modified polyethersulfone membranes. Separ. Sci. Technol. 48, 1627-1635. (60) Yue, W.-W., Xiang, T., Zhao, W.-F., Sun, S.-D., and Zhao, C.-S. (2013) Preparation and characterization of ph-sensitive polyethersulfone membranes blended with poly(methyl methacrylate-co-maleic anhydride) copolymer. Separ. Sci. Technol. 48, 1941-1953.

(61) Yin, X., and Stöver, H. D. H. (2002) Thermosensitive and pH-sensitive polymers based on maleic anhydride copolymers. Macromolecules 35, 1017810181.

(62) Allard, L., Cheynet, V., Oriol, G., Gervasi, G., Imbert-Laurenceau, E., Mandrand, B., Delair, T., and Mallet, F. (2004) Antigenicity of recombinant proteins after regioselective immobilization onto polyanhydride-based copolymers. Bioconjugate Chem. 15, 458-466.

(63) Kaneda, Y., Yamamoto, Y., Tsunoda, S.-i., Kamada, H., Tsutsumi, Y., Hirano, T., and Mayumi, T. (1997) Bioconjugation of tumor necrosis factor- $\alpha$ with the copolymer of divinyl ether and maleic anhydride increasing its antitumor potency. Biochem. Biophys. Res. Commun. 239, 160-165.

(64) Nita, L. E., Chiriac, A. P., Mititelu-Tartau, L., Stoleru, E., Doroftei, F., and Diaconu, A. (2015) Patterning poly(maleic anhydride-co-3,9-divinyl-2,4,8,10tetraoxaspiro (5.5) undecane) copolymer bioconjugates for controlled release of drugs. Int. J. Pharm. 493, 328-340.

(65) Popescu, I., Pelin, I. M., and Suflet, D. M. (2018) Dual-responsive hydrogels based on maleilated curdlan-graft-poly(N-isopropylacrylamide). Int. J. Polym. Mater. PO 67, 1069-1079.

(66) Guo, B., Yuan, J., and Gao, Q. (2007) Preparation and characterization of pH sensitive comb-shaped chitosan material for the controlled release of coenzyme A. J. Mater. Sci.-Mater. M. 18, 753-757.

(67) Miao, Y., Qiu, Y., Yang, W., Guo, Y., Hou, H., Liu, Z., and Zhao, X. (2018) Charge reversible and biodegradable nanocarriers showing dual $\mathrm{pH}$-/reduction-sensitive disintegration for rapid site-specific drug delivery. Colloids Surf. B 169, 313-320. (68) Castelli, F., Sarpietro, M. G., Micieli, D., Ottimo, S., Pitarresi, G., Tripodo, G., Carlisi, B., and Giammona, G. (2008) Differential scanning calorimetry study on drug release from an inulin-based hydrogel and its interaction with a biomembrane model: pH and loading effect. Eur. J. Pharm. Sci. 35, 76-85.

(69) Mandracchia, D., Trapani, A., Perteghella, S., Sorrenti, M., Catenacci, L., Torre, M. L., Trapani, G., and Tripodo, G. (2018) pH-sensitive inulin-based nanomicelles for intestinal site-specific and controlled release of celecoxib. Carbohyd. Polym. $181,570-578$.

(70) Namkung, S., and Chu, C.-C. (2006) Effect of solvent mixture on the properties of temperature- and $\mathrm{pH}$-sensitive polysaccharide-based hydrogels. $J$. Biomat. Sci.-Polym. E. 17, 519-546.

(71) Shohraty, F., Moghadam, P. N., Fareghi, A. R., Movagharnezhad, N., and Khalafy, J. (2018) Synthesis and characterization of new pH-sensitive hydrogels based on poly(glycidyl methacrylate-co-maleic anhydride). Adv. Polym. Tech. 37, 120-125. 
(72) Lim, C., Moon, J., Sim, T., Won, W. R., Lee, E. S., Youn, Y. S., and Oh, K. T. (2019) A nano-complex system to overcome antagonistic photo-chemo combination cancer therapy. J. Control. Release 295, 164-173.

(73) Xia, F., Hou, W., Zhang, C., Zhi, X., Cheng, J., de la Fuente, J. M., Song, J., and Cui, D. (2018) pH-responsive gold nanoclusters-based nanoprobes for lung cancer targeted near-infrared fluorescence imaging and chemo-photodynamic therapy. Acta Biomater. 68, 308-319.

(74) Liu, Y.-Y., and Fan, X.-D. (2002) Synthesis and characterization of pH- and temperature-sensitive hydrogel of $\mathrm{N}$-isopropylacrylamide/cyclodextrin based copolymer. Polymer 43, 4997-5003.

(75) Wang, Y., Yang, N., Wang, D., He, Y., Chen, L., and Zhao, Y. (2018) Poly (MAH$\beta$-cyclodextrin-co-NIPAAm) hydrogels with drug hosting and thermo/pHsensitive for controlled drug release. Polym. Degrad. Stabil. 147, 123-131. (76) Wang, Q., Li, S., Liu, H., Zhang, H., and Li, C. (2009) The molecular inclusion function and $\mathrm{pH}$-sensitivity of hydrogel as a novel drug delivery system. J. Drug Deliv. Sci. Tec. 19, 145-150.

(77) Baydar, A. E., Boyd, G. V., Aupers, J., and Lindley, P. F. (1981) The action of amines on citraconic anhydride. X-Ray crystal structure of (Z)-2-methyl-3pyrrolidinocarbonylpropenoic acid. J. Chem. Soc. Perk. T. 1, 2890-2894. (78) Murali, R., Surya Prakash Rao, H., and Scheeren, H. W. (2001) Intramolecular Diels-Alder reactions of citraconamic acids from furfurylamines and citraconic anhydride: effects of substitution in the furan ring on regioselectivity. Tetrahedron 57, 3165-3174.

(79) Su, S., Du, F.-S., and Li, Z.-C. (2017) Synthesis and pH-dependent hydrolysis profiles of mono- and dialkyl substituted maleamic acids. Org. Biomol. Chem. 15, 8384-8392.

(80) Liu, P., Xu, G., Pranantyo, D., Xu, L. Q., Neoh, K.-G., and Kang, E.-T. (2018) pHsensitive zwitterionic polymer as an antimicrobial agent with effective bacterial targeting. ACS Biomater. Sci. Eng. 4, 40-46.

(81) Mok, H., Park, J. W., and Park, T. G. (2008) Enhanced intracellular delivery of quantum dot and adenovirus nanoparticles triggered by acidic $\mathrm{pH}$ via surface charge reversal. Bioconjugate Chem. 19, 797-801.

(82) Mok, H., Veiseh, O., Fang, C., Kievit, F. M., Wang, F. Y., Park, J. O., and Zhang, M. (2010) pH-sensitive siRNA nanovector for targeted gene silencing and cytotoxic effect in cancer cells. Mol. Pharm. 7, 1930-1939.

(83) Lee, Y., Fukushima, S., Bae, Y., Hiki, S., Ishii, T., and Kataoka, K. (2007) A protein nanocarrier from charge-conversion polymer in response to endosomal pH. J. Am. Chem. Soc. 129, 5362-5363.

(84) Mu, Y., Wu, G., Su, C., Dong, Y., Zhang, K., Li, J., Sun, X., Li, Y., Chen, X., and Feng, C. (2019) pH-sensitive amphiphilic chitosan-quercetin conjugate for intracellular delivery of doxorubicin enhancement. Carbohyd. Polym. 223, 115072.

(85) Yuan, F., Wang, S., Chen, G., Tu, K., Jiang, H., and Wang, L.-Q. (2014) Novel chitosan-based $\mathrm{pH}$-sensitive and disintegrable polyelectrolyte nanogels. Colloids Surf. B 122, 194-201.

(86) Zhang, K., Yang, W., Wang, D., Liu, C., Qi, L., and Wang, Y. (2011) Tumortargeted drug carriers and their enhanced intracellular delivery by $\mathrm{pH}$-sensitivity. J. Control. Release 152, e95-e97. 
(87) Zhou, T., Luo, T., Song, J., and Qu, J. (2018) Phasor-fluorescence lifetime imaging microscopy analysis to monitor intercellular drug release from a $\mathrm{pH}$ sensitive polymeric nanocarrier. Anal. Chem. 90, 2170-2177.

(88) Drummond, D. C., and Daleke, D. L. (1995) Synthesis and characterization of $\mathrm{N}$-acylated, pH-sensitive 'caged' aminophospholipids. Chem.Phys.Lipids 75, 27-41. (89) Reddy, J. A., and Low, P. S. (2000) Enhanced folate receptor mediated gene therapy using a novel pH-sensitive lipid formulation. J. Control. Release 64, 27-37. (90) Pamfil, D., Nistor, M. T., Zemljič, L. F., Vereştiuc, L., Cazacu, M., and Vasile, C. (2014) Preparation and characterization of methyl substituted maleic anhydride: modified collagens destined for medical applications. Ind. Eng. Chem. Res. 53, 3865-3879.

(91) Dror, M., and Levy, M. (1975) Polyimides derived from cyclooctadiene dianhydrides. J. Polym. Sci. Polym. Chem. Ed. 13, 171-187.

(92) Corrie, J. E. T., Moore, M. H., and Wilson, G. D. (1996) Product diversity in cyclisations of maleamic acids: the imide-isoimide dichotomy. J. Chem. Soc. Perk. T. 1, 777-781.

(93) Du, J.-Z., Li, H.-J., and Wang, J. (2018) Tumor-acidity-cleavable maleic acid amide (TACMAA): A powerful tool for designing smart nanoparticles to overcome delivery barriers in cancer nanomedicine. Accounts Chem. Res. 51, 2848-2856. (94) Qu, J., Peng, S., Wang, R., Yang, S.-t., Zhou, Q.-h., and Lin, J. (2019) Stepwise $\mathrm{pH}$-sensitive and biodegradable polypeptide hybrid micelles for enhanced cellular internalization and efficient nuclear drug delivery. Colloids Surf. B 181, 315-324.

(95) Chen, J., Ding, J., Zhang, Y., Xiao, C., Zhuang, X., and Chen, X. (2015) Polyion complex micelles with gradient $\mathrm{pH}$-sensitivity for adjustable intracellular drug delivery. Polym. Chem. 6, 397-405.

(96) Li, X.-X., Chen, J., Shen, J.-M., Zhuang, R., Zhang, S.-Q., Zhu, Z.-Y., and Ma, J.-B. (2018) $\mathrm{pH}$-Sensitive nanoparticles as smart carriers for selective intracellular drug delivery to tumor. Int. J. Pharm. 545, 274-285.

(97) Li, Y., Yang, J., Xu, B., Gao, F., Wang, W., and Liu, W. (2015) Enhanced therapeutic siRNA to tumor cells by a $\mathrm{pH}$-sensitive agmatine-chitosan bioconjugate. ACS Appl. Mater. Inter. 7, 8114-8124.

(98) Zhao, X., Wei, Z., Zhao, Z., Miao, Y., Qiu, Y., Yang, W., Jia, X., Liu, Z., and Hou, H. (2018) Design and development of graphene oxide nanoparticle/chitosan hybrids showing $\mathrm{pH}$-sensitive surface charge-reversible ability for efficient intracellular doxorubicin delivery. ACS Appl. Mater. Inter 10, 6608-6617. (99) Wu, W., Chen, M., Wang, J., Zhang, Q., Li, S., Lin, Z., and Li, J. (2014) Nanocarriers with dual $\mathrm{pH}$-sensitivity for enhanced tumor cell uptake and rapid intracellular drug release. RSC Adv. 4, 30780-30783.

(100) Huang, X., Cao, J., Zhang, Y., Liu, T., and Yan, H. (2019) Polyethylenimine modified with 2,3-dimethylmaleic anhydride potentiates the antitumor efficacy of conventional chemotherapy. Mater. Sci. Eng. C 102, 558-568.

(101) Han, S.-S., Li, Z.-Y., Zhu, J.-Y., Han, K., Zeng, Z.-Y., Hong, W., Li, W.-X., Jia, H.-Z., Liu, Y., Zhuo, R.-X., and Zhang, X.-Z. (2015) Dual-pH sensitive charge-reversal polypeptide micelles for tumor-triggered targeting uptake and nuclear drug delivery. Small 11, 2543-2554.

(102) Kamada, H., Tsutsumi, Y., Yoshioka, Y., Yamamoto, Y., Kodaira, H., Tsunoda, S.-i., Okamoto, T., Mukai, Y., Shibata, H., Nakagawa, S., and Mayumi, T. (2004) 
Design of a pH-Sensitive polymeric carrier for drug release and its application in cancer therapy. Clin. Cancer Res. 10, 2545.

(103) Dinand, E., Zloh, M., and Brocchini, S. (2002) Competitive reactions during amine addition to cis-aconityl anhydride. Aust. J. Chem. 55, 467-474.

(104) Shen, W.-C., and Ryser, H. J. P. (1981) Cis-aconityl spacer between

daunomycin and macromolecular carriers: A model of $\mathrm{pH}$-sensitive linkage

releasing drug from a lysosomotropic conjugate. Biochem. Biophys. Res. Commun. 102, 1048-1054.

(105) Reményi, J., Balázs, B., Tóth, S., Falus, A., Tóth, G., and Hudecz, F. (2003)

Isomer-dependent daunomycin release and in vitro antitumour effect of cisaconityl-daunomycin. Biochem. Biophys. Res. Commun. 303, 556-561.

(106) Kamps, J. A. A. M., Morselt, H. W. M., Swart, P. J., Meijer, D. K. F., and Scherphof, G. L. (1997) Massive targeting of liposomes, surface-modified with anionized albumins, to hepatic endothelial cells. Proc. Natl Acad. Sci. USA 94, 11681-11685.

(107) Du, C., Deng, D., Shan, L., Wan, S., Cao, J., Tian, J., Achilefu, S., and Gu, Y. (2013) A pH-sensitive doxorubicin prodrug based on folate-conjugated BSA for tumor-targeted drug delivery. Biomaterials 34, 3087-3097.

(108) Fang, X.-B., Zhang, J.-M., Xie, X., Liu, D., He, C.-W., Wan, J.-B., and Chen, M.-W. (2016) pH-sensitive micelles based on acid-labile pluronic F68-curcumin conjugates for improved tumor intracellular drug delivery. Int. J. Pharm. 502, 2837.

(109) Mollaev, M., Gorokhovets, N., Nikolskaya, E., Faustova, M., Zabolotsky, A., Zhunina, O., Sokol, M., Zamulaeva, I., Severin, E., and Yabbarov, N. (2019) Type of $\mathrm{pH}$ sensitive linker reveals different time-dependent intracellular localization, in vitro and in vivo efficiency in alpha-fetoprotein receptor targeted doxorubicin conjugate. Int. J. Pharm. 559, 138-146.

(110) Wu, J., Tang, C., and Yin, C. (2017) Co-delivery of doxorubicin and interleukin-2 via chitosan based nanoparticles for enhanced antitumor efficacy. Acta Biomater. 47, 81-90.

(111) Xu, C., Wang, P., Zhang, J., Tian, H., Park, K., and Chen, X. (2015) Pulmonary codelivery of doxorubicin and siRNA by $\mathrm{pH}$-sensitive nanoparticles for therapy of metastatic lung cancer. Small 11, 4321-4333.

(112) Xu, X.-Y., Chen, Y.-F., Tan, Q.-G., Chen, Z.-J., Li, Y., Wu, W.-G., Wang, X.-F., and Liu, Y.-B. (2019) Construction of multilayer films with bactericidal and long-term antitumor drug release properties as a non-vascular stent coating for therapy in obstruction. J. Mater. Chem. B 7, 4963-4972.

(113) Xu, S. S., Wu, J., and Jiang, W. (2015) Synthesis and characterisation of a pHsensitive magnetic nanocomposite for controlled delivery of doxorubicin. J. Microencapsul. 32, 533-537.

(114) Zhi, X., Liu, Y., Lin, L., Yang, M., Zhang, L., Zhang, L., Liu, Y., Alfranca, G., Ma, L., Zhang, Q., Fu, H., Conde, J., Ding, X., Chen, D., Ni, J., Song, J., and Cui, D. (2019) Oral pH sensitive GNS@ab nanoprobes for targeted therapy of Helicobacter pylori without disturbance gut microbiome. Nanomedicine: NBM 20, 102019, https://doi.org/10.1016/j.nano.2019.102019.

(115) Yang, H. M., and Reisfeld, R. A. (1988) Doxorubicin conjugated with a monoclonal antibody directed to a human melanoma-associated proteoglycan 
suppresses the growth of established tumor xenografts in nude mice. Proc. Natl Acad. Sci. USA 85, 1189-1193.

(116) Cong, Y., Ji, L., Gao, Y.-J., Liu, F.-H., Cheng, D.-B., Hu, Z., Qiao, Z.-Y., and Wang, H. (2019) Microenvironment-induced in situ self-assembly of polymer-peptide conjugates that attack solid tumors deeply. Angew. Chem. Int. Ed. 58, 4632-4637. (117) Lee, Y., Miyata, K., Oba, M., Ishii, T., Fukushima, S., Han, M., Koyama, H., Nishiyama, N., and Kataoka, K. (2008) Charge-conversion ternary polyplex with endosome disruption moiety: a technique for efficient and safe gene delivery. Angew. Chem. Int. Ed. 47, 5163-5166.

(118) Hou, W., Zhao, X., Qian, X., Pan, F., Zhang, C., Yang, Y., de la Fuente, J. M., and Cui, D. (2016) pH-Sensitive self-assembling nanoparticles for tumor near-infrared fluorescence imaging and chemo-photodynamic combination therapy. Nanoscale 8, 104-116.

(119) Sun, D., Ding, J., Xiao, C., Chen, J., Zhuang, X., and Chen, X. (2015) pHResponsive reversible pegylation improves performance of antineoplastic agent. Adv. Healthc. Mater. 4, 844-855.

(120) Yoo, H. S., Lee, E. A., and Park, T. G. (2002) Doxorubicin-conjugated biodegradable polymeric micelles having acid-cleavable linkages. J. Control. Release 82, 17-27.

(121) Zhu, S., Hong, M., Tang, G., Qian, L., Lin, J., Jiang, Y., and Pei, Y. (2010) Partly PEGylated polyamidoamine dendrimer for tumor-selective targeting of doxorubicin: The effects of PEGylation degree and drug conjugation style. Biomaterials 31, 1360-1371.

(122) Choi, W.-M., Kopečková, P., Minko, T., and Kopeček, J. (1999) Synthesis of HPMA copolymer containing adriamycin bound via an acid-labile spacer and its activity toward human ovarian carcinoma cells. J. Bioact. Compat. Polym. 14, 447456.

(123) Maeda, Y., Pittella, F., Nomoto, T., Takemoto, H., Nishiyama, N., Miyata, K., and Kataoka, K. (2014) Fine-tuning of charge-conversion polymer structure for efficient endosomal escape of siRNA-loaded calcium phosphate hybrid micelles. Macromol. Rapid Comm. 35, 1211-1215.

(124) Kang, S., Park, E., Kim, Y., Lee, S., Kwon, J., Cho, H., and Lee, Y. (2014) A medusa-like beta-cyclodextrin with 1-methyl-2-(2'-carboxyethyl) maleic anhydrides, a potential carrier for $\mathrm{pH}$-sensitive drug delivery. J. Drug Target. 22, 658-668.

(125) Li, H.-J., Du, J.-Z., Du, X.-J., Xu, C.-F., Sun, C.-Y., Wang, H.-X., Cao, Z.-T., Yang, X.Z., Zhu, Y.-H., Nie, S., and Wang, J. (2016) Stimuli-responsive clustered nanoparticles for improved tumor penetration and therapeutic efficacy. Proc. Natl Acad. Sci. USA 113, 4164-4169.

(126) Song, Y., Jung, D., Kang, S., and Lee, Y. (2017) Amine-selective affinity resins based on $\mathrm{pH}$-sensitive reversible formation of covalent bonds. Soft matter 13, 2295-2298.

(127) Suma, T., Cui, J., Müllner, M., Ju, Y., Guo, J., Hu, M., and Caruso, F. (2015) Generalizable strategy for engineering protein particles with $\mathrm{pH}$-triggered disassembly and recoverable protein functionality. ACS Macroletters, 160-164. (128) Takemoto, H., Miyata, K., Hattori, S., Ishii, T., Suma, T., Uchida, S., Nishiyama, N., and Kataoka, K. (2013) Acidic pH-responsive siRNA conjugate for reversible 
carrier stability and accelerated endosomal escape with reduced IFNa-associated immune response. Angew. Chem. Int. Ed. 52, 6218-6221.

(129) Wang, W., Li, L., Jin, C., Niu, Y., Li, S., Ma, J., Li, L., Liu, Y., Cai, L., Zhao, W., and Wang, P. G. (2011) Enzymatic synthesis of a 6-sialyl lactose analogue using a pHresponsive water-soluble polymer support. Bioorg. Med. Chem. Lett. 5041-5044. (130) Zhang, A., Yao, L., and An, M. (2017) Reversing the undesirable pH-profile of doxorubicin via activation of a di-substituted maleamic acid prodrug at tumor acidity. Chem. Commun. 53, 12826-12829.

(131) Goh, Y. W., Danczak, S. M., Lim, T. K., and White, J. M. (2007) Manifestations of the Alder-Rickert reaction in the structures of bicyclo[2.2.2] octadiene and bicyclo[2.2.2] octene derivatives. J. Org. Chem. 72, 2929-2935.

(132) Kim, H., Kim, S., Kang, S., Song, Y., Shin, S., Lee, S., Kang, M., Nam, S. H., and Lee, Y. (2018) Ring opening metathesis polymerization of bicyclic alpha, betaunsaturated anhydrides for ready-to-be-grafted polymers having tailored $\mathrm{pH}$ responsive degradability. Angew. Chem. Int. Ed. 57, 12468-12472.

(133) Liu, G.-Y., Li, M., Zhu, C.-S., Jin, Q., Zhang, Z.-C., and Ji, J. (2014) Chargeconversional and $\mathrm{pH}$-sensitive PEGylated polymeric micelles as efficient nanocarriers for drug delivery. Macromol. Biosci. 14, 1280-1290.

(134) Zhang, W., Liu, X., Zhao, X., and Zhang, X. (2017) Controllable delivery of peptides by superparamagnetic $\mathrm{Fe}_{3} \mathrm{O}_{4}$ /slica nanoparticle vehicles. Mater. Lett. 201, 177-180.

(135) Zhang, X., Clime, L., Roberge, H., Normandin, F., Yahia, L. H., Sacher, E., and Veres, T. (2011) pH-Triggered doxorubicin delivery based on hollow nanoporous silica nanoparticles with free-standing superparamagnetic $\mathrm{Fe}_{3} \mathrm{O}_{4}$ cores. J. Phys. Chem. C 115, 1436-1443.

(136) Ma, Y., Gao, H., Gu, W., Yang, Y.-W., Wang, Y., Fan, Y., Wu, G., and Ma, J. (2012) Carboxylated poly(glycerol methacrylate)s for doxorubicin delivery. Eur. J. Pharm. Sci. 45, 65-72.

(137) Wang, Y., Wang, H., Lv, X., Liu, C., Qi, L., Song, X., and Yu, A. (2014)

Enhancement of all-trans retinoic acid-induced differentiation by $\mathrm{pH}$-sensitive nanoparticles for solid tumor cells. Macromol. Biosci. 14, 369-379.

(138) Sasaki, T., Minamoto, K., and Itoh, H. (1978) Convenient synthesis of some purine 8,5'-imino cyclonucleosides. J. Org. Chem. 43, 2320-2325.

(139) Song, H.-Y., Yao, J.-H., Liu, J.-Z., Zhou, S.-J., Xiong, Y.-H., and Ji, L.-N. (2005) Effects of phthalic anhydride modification on horseradish peroxidase stability and structure. Enzyme Microb. Tech. 36, 605-611.

(140) Yuen, J., Chai, J., and Ding, Y. (2020) Condensation of DNA-conjugated imines with homophthalic anhydride for the synthesis of isoquinolones on DNA. Bioconjugate Chem. 31, 2712-2718.

(141) Brouillette, Y., Martinez, J., and Lisowski, V. (2009) Chemistry of ring-fused oxazine-2,4-diones. Eur. J. Org. Chem. 3497-3503.

(142) Fessler, A. B., Dey, A., Garmon, C. B., Finis, D. S., Saleh, N.-A., Fowler, A. J., Jones, D. S., Chakrabarti, K., and Ogle, C. A. (2018) Water-soluble isatoic anhydrides: a platform for RNA-SHAPE analysis and protein bioconjugation. Bioconjugate Chem. 29, 3196-3202.

(143) Gondi, S. R., Bera, A. K., and Westover, K. D. (2019) Green synthesis of substituted anilines and quinazolines from isatoic anhydride-8-amide. Sci. Rep. 9, 14258, https://doi.org/10.1038/s41598-019-50776-y 
(144) Hasegawa, M., Saito, T., and Tsujimura, Y. (2020) Poly(ester imide)s possessing low coefficients of thermal expansion and low water absorption (IV): Effects of ester-linked tetracarboxylic dianhydrides with longitudinally extended structures. Polym. Adv. Technol. 31, 389-406.

(145) Nguyen, H. L., Gropp, C., and Yaghi, O. M. (2020) Reticulating 1D ribbons into 2D covalent organic frameworks by imine and imide linkages. J. Am. Chem. Soc. 142, 2771-2776.

(146) Shende, P., Vaidya, J., and Kulkarni, Y. A. (2019) Bio-inspired nanoengineered strip for semiquantitative FeNO analysis. J. Breath Res. 13, 046002. (147) Zhang, H., Majumdar, S., van Benthem, R. A. T. M., Sijbesma, R. P., and Heuts, J. P. A. (2020) Intramolecularly catalyzed dynamic polyester networks using neighboring carboxylic and sulfonic acid groups. ACS Macro Lett. 9, 272-277.

Table of Contents Graphic

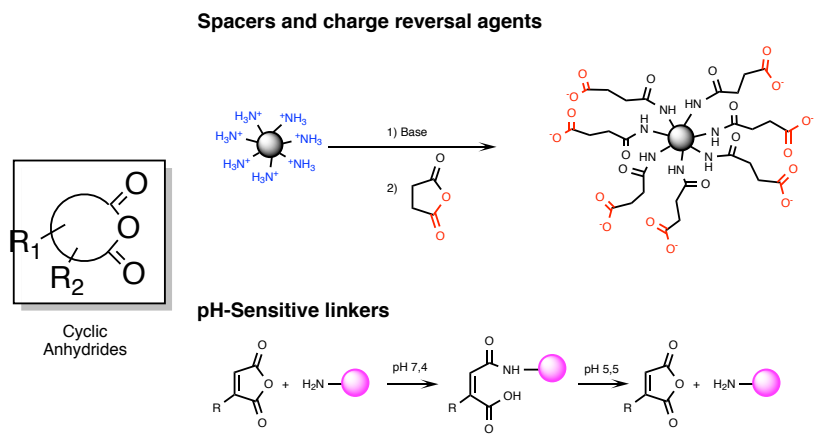

